\title{
Progressive collapse resistance of steel self-centering MRFs including the effects of the composite floor
}

\author{
Christoforos A. Dimopoulos ${ }^{1 *}$, Fabio Freddi ${ }^{2}$, Theodore L. Karavasilis ${ }^{3}$ and George Vasdravellis ${ }^{4}$ \\ ${ }^{1}$ Lecturer, School of Science, Engineering \& Design, Teesside University, Middlesbrough, TS1 3BX, \\ U.K. *Corresponding Author. E-mail address: c.dimopoulos@tees.ac.uk \\ ${ }^{2}$ Lecturer, Dept. of Civil, Environmental \& Geomatic Engineering, Univ. College of London, London \\ WC1E 6BT, U.K. Tel.: +44 (0)7752360204. E-mail address: f.freddi@ucl.ac.uk \\ ${ }^{3}$ Associate Professor in Steel Structures, Department of Civil Engineering, University of Patras, GR- \\ 26500 Patras, Greece, E-mail address: karavasilis@upatras.gr \\ ${ }^{4}$ Associate Professor, Institute for Infrastructure and Environment, Heriot-Watt University, EH14 \\ 4AS, UK, Email address: g.vasdravellis@hw.ac.uk
}

\begin{abstract}
This paper presents progressive collapse simulations to assess the robustness of a seismicresistant building using self-centering moment resisting frames (SC-MRFs) under a sudden column loss scenario. The first floor of the building, including the composite floor, was modelled in ABAQUS using a mixture of finite element types and simulation methods to balance computational cost and accuracy. First, key components of the numerical model, including the composite beams, the fin-plate beam-column connections, and the perimeter SC-MRFs, were validated against available experimental results to ensure a reliable simulation. The validated model was then used to study the robustness of the building under a sudden column loss event. Both nonlinear static and dynamic analyses were employed. The simulations allowed for the identification of all possible failure modes and the quantification of the contribution of the composite floor to the robustness of the frame. The results show that the building can withstand the code-prescribed load with a safety factor of 2 and that the structural limit state that triggers progressive collapse is the buckling of the gravity columns. The Dynamic Increase Factor (DIF) was also identified by comparing the static and dynamic responses.
\end{abstract}

Keywords: Steel Structures; Self-Centering Moment Resisting Frames; Progressive collapse; Dynamic Increase Factor; Robustness. 


\section{INTRODUCTION}

Conventional seismic-resistant structures, such as steel moment-resisting frames (MRFs), are designed to experience significant inelastic deformations under strong earthquakes $[1,2]$. Inelastic deformations result in damage of structural members and residual interstory drifts, which lead to high repair costs and disruption of the building use or occupation. The aforementioned socio-economic risks highlight the need for widespread implementation of minimal-damage structures, which can reduce both repair costs and downtime. Amongst others, steel frames equipped with self-centering beam-column connections with posttensioned high strength bars [e.g., 3, 4, 5, 6, 7, 8] demonstrated their superior seismic performance, i.e., in minimizing the damage in the main structural components and in providing self-centering capability even under strong earthquakes.

However, specialization of the structure in order to improve the seismic performances should not affect its capability to resists other types of hazard. Multi-hazard considerations are required to account holistically for the different threats to which a structure may be exposed [e.g., 9,10$]$.

Amongst others, man-made hazards deriving from events such as fire, explosions, impact or the consequences of human errors and any kind of event that could produce a sudden loss of a load carrying component gained the attention of many researchers in the last decades because of the possibility of progressive collapse [11]. Progressive collapse of a structure occurs when the failure of a structural component, leads to the collapse of the surrounding members, promoting additional collapse.

Fundamental characteristics such as stiffness, strength, ductility and stability of a structure are conventionally controlled through codified design procedures with the aim of meeting specific requirements. However, during their life span, structures could be exposed to some accidental events which are outside the coverage of normal design processes. These events are unpredictable in terms of cause, probability of occurrence and intensity and hence is not feasible, nor practical or economical to include their effects in the design procedure. A more rational and well recognized approach is to provide the structure with the ability to withstand such events, without being damaged to an extent disproportionate to the original cause [12].

Several disasters of different origin made the interest in the response of structures subjected to extreme loads such as impact or blast to continuously grow. Amongst cases with higher relevance are the collapse of the Ronan Point Building (London, 1968) [13], of the Murrah Federal Building (Oklahoma City, 1995) [14] and of the World Trade Center (New York, 2001) [15]. Many research studies focus on this subject since 1940 [e.g., 16, 17, 18] and allowed to build up an increasing understanding of the structural response and the definition of possible design strategies that nowadays are incorporated in design specifications and codes $[12,19,20]$.

However, very limited research has been carried out on SC-MRFs and on steel and steelconcrete composite structures overall. No practical rules are available allowing the exploitation of their high bearing capacity and significant ductility. The current research mainly focused on impact investigations of single steel members and very few studies 
accounted for the influence of the supports and of the surrounding structure whereas the continuity of the members and the floor $3 \mathrm{D}$ actions represent essential factors ensuring a robust structural response. Demonceau and Jaspart (2013) [21] experimentally tested a 2D steel-concrete composite frame composed by composite beams, steel columns and partial strength composite joints under the central column collapse. The test indicated the important contribution of the ductile behavior of the configuration allowing the development of catenary action in the beams. Yang and Tan (2013) [22] experimentally evaluated the performance of several types of the most common bolted steel beam-column connections under the column loss scenario. The results showed that the tensile capacity of the beamcolumn joints after large rotations is the main parameter that determines the failure of the system. Despite both these studies do not focus on the behavior of self-centering beamcolumn connections with post-tensioned high strength bars, they highlight the benefits of some characteristics proper of this type of connection such as their high rotational capacity. Wang et al. (2017) [23] performed an experimental and computational study on two composite subassemblies under a column removal scenario. The two specimens, designed as beam-joint-beam subassemblies with composite reinforced concrete slabs, were tested under sagging and hogging deflections simulating the behavior of the joint in the position of the 'removed' column or in the joint adjacent to the 'removed' column respectively. To investigate slab effects, the test results were compared with experimental results on steel subassemblies similar to the test specimens but without slab. The load carrying capacities of the composite subassemblies were $63 \%$ higher than the steel subassemblies only.

The illustrated studies focused on the 2D behavior only, while the frame system in the orthogonal direction provides important alternative load paths that need to be investigated. Dinu et al. (2016) [24] experimentally investigated the capacity of a 3D steel frame structure to support the loss of a central column. A scaled-down specimen with two bays and two spans was extracted from a six-story steel moment-frame building. Extended end-plate bolted beam-column connections were designed as fully rigid connections and the test was performed by applying a monotonic load to the top of the central column until complete failure. The study focused on steel frames with this type of connections to develop catenary action under column loss. The beam-column connections showed very good behavior and had sufficient strength to resist the catenary forces developed in the beams. However, the membrane actions in the slab were not considered in this study.

Zandonini et al. (2019) [25] investigated the influence of the frame continuity and of the floor system in the development of 3D membrane action. Two geometrically different 3D steelconcrete composite full-scale substructures were tested by simulating the column collapse scenario. The test results show the important contribution of the slab to the load redistribution from the damaged to the undamaged parts of the structure allowing a robust structural response. Jahromi et al. (2012) [26] performed an interior column removal test on a full-scale composite floor specimen composed by two-bays, two-spans and one-story prototype building. The test results showed that the floor system could resist loads up to 1.6 times the ASCE 7-10 [27] extreme event load combination. Also, in this case the building is composed by steel framed structure with simple connections (i.e., double angle and shear tab connections) and a concrete floor slab poured over corrugated steel decking. 
Besides the experimental campaigns, several researchers [e.g., 30, 31, 32, 33, 34, 35, 36] used computational models to investigate the structure's performance under the column loss scenario. These computational studies allowed further evaluation of the critical behavior associated with the joints and membrane action in the slab in the large vertical displacements range. The effects of some important parameters such as deck thickness, steel reinforcement and numbers of bolts in the shear tab connections on the behavior of the structural system are investigated as a function of the loading scheme. Reduced models are also developed and compared with detailed model results in order to enables studies on large multi-bay systems. A detailed literature review on the progressive collapse of frame buildings is reported in Adams et al. (2018) [11].

Research on the structural robustness of SC-MRFs is limited on few studies. Tsitos and Mosqueda (2011) [37] performed a quasi-static 'push-down' experiment to evaluate the progressive collapse resistance of steel buildings with SC-MRFs considering the column loss scenario. A 1:3 scaled three-story, two-bay SC-MRF designed and previously tested for seismic performance on a shaking table, was experimentally tested simulating the sudden failure of a base column. The objective of the tests was to evaluate the effectiveness of earthquake resistant design details in enhancing the resistance to progressive collapse and was observed that the vertical load carrying capacity of the frame depends primarily on the performance and ultimate strength of the tendons.

Pirmoz and Liu (2016) [38] numerically investigated the structural behavior of SC-MRFs in redistributing the unbalanced gravity loads due to column removal. High-fidelity finite element structural models were constructed and validated using the available experimental data in the literature. The capacity of post-tensioned (PT) steel frames subjected to a gradually increasing vertical displacement along the 'removed' column line was systematically studied. The results showed that beam arching action and strand catenary action are the major sources of structural capacity of a PT steel frame against progressive collapse. The corresponding failure modes were identified, and the design implications suggested.

Vasdravellis et al. (2018) [39] studied the robustness of a planar SC-MRF with highly ductile optimized hourglass shape energy dissipation devices (WHPs) under column loss. They found that the PT bars catenary action and the high fracture capacity of the WHPs significantly contribute to the progressive collapse resistance of the frame. It was also found that the WHPs can be designed in such a way that they do not fracture under connection rotations up to $0.2 \mathrm{rad}$.

Ghorbanzadeh et al (2019) [40] proposed recently a set of novel structural details that can be added to industry-standard nominally pinned joints to increase both their tensile resistance and rotation capacity as an effective scheme for enhancement of existing weak fin-plate connections. The proposed structural details exploited the exceptional strength and ductility of duplex stainless-steel pins (SSPs) under bending [41].

The resistance to progressive collapse of SC-MRFs including the effects of the composite floor in a three-dimensional context is not studied yet and is the focus of this paper. The first floor of the building was modelled in ABAQUS, including the composite floor, using a 
mixture of finite element types and simulation methods to balance computational cost and accuracy. Appropriate boundary restraints were included in the model in order to simulate the continuity of the columns to the upper stories as done previous studies [e.g., 42, 43]. Key components of the numerical model, including the composite beams, the fin-plate beamcolumn connections, and the perimeter SC-MRFs, were validated against previous experimental results to ensure the accuracy of the numerical results. The validated model allowed to investigate the robustness of the building under the sudden loss of an internal column of the SC-MRF. The simulations allowed for the identification of all possible failure modes, and the quantification of the contribution of the composite floor to the robustness of the frame. The results showed that the building can withstand the code-prescribed load, calculated according to the UFC [19], with a safety factor of 2, and that the limiting factor leading to its progressive collapse is the buckling of the gravity columns. Both nonlinear static and dynamic analyses were employed allowing the identification of the Dynamic Increase Factor (DIF).

\section{PROTOTYPE BUILDING}

A five-story building with SC-MRFs using PT connections and WHPs [5] was used as the prototype frame of this study. The plan view and elevations are shown in Fig. 1. The frame uses two perimeter SC-MRFs to resist seismic loads in the X direction, while concentrically braced frames are used in the Y direction. The interior frames were designed for gravity loads only and with fin-plate connections. The column loss scenario is simulated on an internal column of the SC-MRF (column A3) as reported in Fig. 1(a).

The SC-MRFs consists on steel beams that are clamped to the columns by two high strength PT steel bars located at the mid depth of the beam, one at each side of the beam web, passing through holes drilled on the column flanges as illustrated in Fig. 2. The seismic energy is dissipated through the inelastic bending of the WHPs while the self-centering behavior is achieved by the restoring forces due to the elastic elongation of the PT bars as the gaps open and close at the beam-column interfaces. WHPs are inserted in aligned holes on the beam web and on supporting plates welded to the column flanges. More details on the seismic response of the SC-MRF of the case study building can be found in [4] and [5].

The horizontal resisting systems were designed to achieve the ultimate and serviceability limit state criteria against seismic actions of Eurocode 8 [1]. The design is based on the Design Basis Earthquake (i.e., probability of exceedance of $10 \%$ in $50 \mathrm{yrs}$ ) characterized by the Type 1 elastic response spectrum of Eurocode 8 , peak ground acceleration equal to $0.35 \mathrm{~g}$, and ground type B. In addition, the maximum inter-story drift ratio was limited to $0.75 \%$ under the Frequently Occurring Earthquake (probability of exceedance of 10\% in $10 \mathrm{yrs}$ ), assuming that the building has ductile non-structural elements.

The concrete slab has a thickness of $120 \mathrm{~mm}$ and is made of C25/30 concrete. Full shear connection was assumed for all the composite beams, using shear studs, designed according to EN1994-1-1 [50], with a diameter and length of $19 \mathrm{~mm}$ and $100 \mathrm{~mm}$, respectively. Following the configuration proposed in [5], in order to allow for unrestricted frame 
expansion due to gap opening, and hence the concrete slab to slide on the steel sections, no shear studs were used in the main beams in lines 2 to 5 of Fig. 1. The number of shear connectors considered in the secondary beams and in the main beams in the $\mathrm{X}$ directions are given in Fig. 1. An elevation view of the SC-MRF and details of the PT beam-column connections are given in Fig. 2.

The dead load (DL), including the weight of the concrete slab, electrical/mechanical equipment, and internal light partitions, was assumed equal to $5 \mathrm{kN} / \mathrm{m}^{2}$ in the design. A surface load for glass cladding equal to $2.1 \mathrm{kN} / \mathrm{m}^{2}$ was assumed as part of the dead load. The live load (LL) was assumed equal to $3 \mathrm{kN} / \mathrm{m}^{2}$, which is a typical value for offices [44].

\section{NUMERICAL MODEL}

\subsection{Description of the model}

A numerical model of the first floor of the prototype building was developed through the finite element method (FEM) software ABAQUS [45]. It employed different element types and modelling techniques to achieve a balance between computational cost and accuracy. An overview of the FEM model is shown in Fig. 3. The SC-MRF of the frame A (Fig. 1), where the column loss is simulated, is modelled in detail through ' $3 D$ solid elements', while the other parts of the structure, farther from the 'removed' column, are modelled by 'frame' and 'shell' elements. This approach allowed to contain the computational cost while not affecting the accuracy of the analysis. The columns are longer than the story height and continue up to the middle height of the second story, where they are constrained from any lateral displacement in order to correctly represent the beam-column joints rotational stiffness at the story level. The column bases were fixed in all directions. Key components of the frame are described in detail in this section.

Constant length mesh of $70 \mathrm{~mm}$ and $100 \mathrm{~mm}$ size was adopted for the B31 Timoshenko elements used for the beam and column frame elements respectively. For the slab an element size of approximately 140 x $190 \mathrm{~mm}$ was considered. The mesh size of 3D solid elements for the columns and beams of the SC-MRF was variable with smaller elements in the regions of expected failure, e.g. at the bottom of the fixed columns or near the end of the beams with typically two elements in the thickness direction and $25 \mathrm{~mm}$ element size in the case of beams and $40 \mathrm{~mm}$ in the case of columns.

In order to investigate the contribution of the frame continuity in the orthogonal direction and of the floor system in the development of 3D membrane actions, three different numerical models have been constructed as reported in Fig. 4, namely: a) Planar frame (Model 1); b) 3D frame (Model 2) and c) 3D frame with slab (Model 3).

In the planar frame (Model 1), where the transverse beams and the concrete slab are not included, a number of points at the top flange of the beams was fixed against transverse displacement (in Y direction as reported in Fig. 1) in order to avoid any lateral buckling.

\subsection{Modelling of the SC-MRFs}


The SC-MRF of the frame A was modelled in full detail. The main structural components of the SC-MRF, i.e., columns, beams, continuity plates for the column panel zone and web and flange beam reinforcing plates, were modelled using '8-node $3 D$ solid elements with reduced integration' (C3D8R) [45]. Only the portion of beams and columns near to their ends was modelled using the '8-node linear brick elements with incompatible modes' (C3D8I) [45] in order to capture the possible local buckling as reported in Fig. 5. The PT bars were modelled using truss elements and were connected to 3D heads/nuts at their ends using multi-pint constraints (MPC). The PT bars pass through holes at the columns' flanges. In order to model the kinematic restrictions that the column flanges pose to the PT bars, a number of constraint equations between PT bars and the holes of the columns' flanges were imposed. An initial strain producing the required PT force was applied to the truss elements representing the PT bars.

Two different modeling techniques for the WHPs were investigated. WHPs and their supporting plates were modelled both in a detailed and a simplified manner. In the first case, the WHPs and the supporting plates were modelled using '8-node 3D solid elements with reduced integration' (C3D8R) [45]. In the simplified model, the two rows of WHPs, i.e., the top and bottom pairs, were replaced by two, at each WHP level, nonlinear-coupled connector elements of 'Cartesian' type, as shown in Fig. 6. 'Cartesian' type connectors in ABAQUS are used to define an elastoplastic force-displacement behavior between two points along three coordinate axes. Each connector fixes a point on the web of the beam with one on the column flange at the level of the corresponding WHP row. The elastoplastic behavior of the connector elements used to replace the bending behavior of each row of WHPs is the multilinear curve in Fig. 7 and is the same along the $\mathrm{Y}$ and $\mathrm{Z}$ axes according to the coordinate system shown in Fig. 1(a). A sudden drop of the force at $110 \mathrm{~mm}$ is defined to indicate fracture and a small residual force is specified after fracture to numerical problems in the analysis. The simplified model was built in order to reduce the computational time without compromising the accuracy of the results.

Contact interactions were specified to describe the behavior among parts of the frame that are in contact, i.e., the WHPs and the supporting plates, the beam and the column flanges. A 'hard' contact for the normal direction and the 'penalty method' with a friction coefficient of 0.4 for the tangential direction were assumed as contact properties. The contact rule adopted followed the 'surface-to-surface' formulation with finite sliding among surfaces [45].

A WHP with $D_{\mathrm{e}}=41 \mathrm{~mm}, D_{\mathrm{i}}=22 \mathrm{~mm}, L_{\mathrm{WHP}}=120 \mathrm{~mm}$ and $f_{\mathrm{y}}=450 \mathrm{MPa}$ was assumed in this study. According to [39], this is an optimized geometry that can maximize the fracture displacement of the WHP and, thus, the rotational capacity of the PT connection.

The stiffness and strength of the WHP were determined by $[47,48]$ :

$$
\begin{aligned}
K_{\mathrm{WHP}} & =2 \frac{9 \pi D_{\mathrm{e}}^{3} D_{\mathrm{i}} E G}{40 E D_{\mathrm{e}}^{2} L_{\mathrm{WHP}}+48 G L_{\mathrm{WHP}}^{3}} \\
F_{\mathrm{WHP}} & =\max \left(\frac{2}{3} \frac{D_{\mathrm{e}}^{3}}{L_{\mathrm{WHP}}} f_{\mathrm{y}, \mathrm{WHP}} ; 1.8 \frac{\pi D_{\mathrm{i}}^{2}}{4} \frac{f_{\mathrm{y}, \mathrm{WHP}}}{\sqrt{3}}\right)
\end{aligned}
$$


In order to make a successful comparison between the detailed and the simplified numerical models, a third numerical model was built containing only one beam-to-column connection with the four WHPs only and without the PT bars. An equivalent load-displacement curve is obtained for the WHPs and is related to the true-stress-strain behavior of the WHPs considered in the detailed 3D numerical model.

\subsection{Modelling of the composite floor}

The concrete slab was modelled using the '4-node general purpose shell element' (S4R) [45]. Elements S4R rely on 'reduced integration' and 'hourglass control'. The steel reinforcement in the concrete slab is simulated via the 'rebar layer' option in ABAQUS by considering a number of parameters (e.g., cross-sectional area of the rebar, spacing of rebar in the plane of the shell elements, position of the rebar in the shell section thickness direction and angular orientation of the rebars). Beams were modelled using the 'B31 Timoshenko beam' [45]. This element, which can be used for both slender and stocky beams, assumes a transverse shear behavior of Timoshenko beams that is linear elastic with a fixed modulus and an independent response of the beam section to axial stretch and bending which can be linear or nonlinear (geometrically and materially).

Connector elements were used to represent the shear studs in the computational model. Shear studs were assumed to connect the middle surface of the concrete slab to the neutral axis of the steel section. The connectors were assigned with a 'Cartesian' and an 'ALIGN' type of behavior for the translational and the rotational degrees of freedom, respectively. Elasticperfectly plastic behavior was assumed for their force-displacement response. The elastic behavior of the connectors in the two orthogonal shear directions was characterized according to [51] by the stiffness provided in Eq. (3):

$$
K_{\text {si }}=\frac{D_{\text {max }}}{d_{\text {sh }}\left(\alpha-0.017 f_{\mathrm{c}}\right)}
$$

where $D_{\max }$ is the maximum dowel strength of the studs, $d_{\mathrm{sh}}$ is the diameter of the shank of the studs, $\alpha$ is equal to $0.08,0.16,0.24$ for upper $95 \%$ characteristic stiffness, mean and lower characteristic stiffness. A value equal to 0.16 was adopted in this study.

The plastic force $F_{\mathrm{y}}$ and the maximum allowable relative displacement $\delta_{\mathrm{u}}$ were calibrated based on the results of previous push-out tests $[52,53]$.The failure of the shear stud was taken into account via the connector failure behavior by setting the maximum value of $\delta_{\mathrm{u}}$ (in this case equal to $7 \mathrm{~mm}$ ). It was chosen for all components of motion to be released upon meeting the failure criterion. The elasto-plastic behavior assumed for the studs in this study is given in Fig. 8. The same behavior was considered in the two transverse directions while for the axial directions a stiffness equal to five times the axial stiffness of the stud was found to provide reasonable results compared to the experimental ones.

\subsection{Modelling of the fin-plate connections}


The interior frames were designed for gravity loads only and employed fin-plate beamcolumn connections. The reduced modelling approach for the fin-plate joints used nonlinear connectors, one for each bolt row in the connection, with distinct load-deformation curves to represent yielding and failure. Although other failure modes may potentially be observed (e.g., fillet weld failure or block shear failure), the governing failure modes for the fin-plate connections considered in this study were the bearing at bolt holes and bolt shear failure.

For the ductile bearing failure at holes, the load-displacement relationship of Fig. 9(a) proposed by Main and Sadek (2014) [54] was adopted. This relationship was controlled by bolt tear out which exhibits a gradual drop in resistance after the ultimate load in tension $\left(t_{\mathrm{u}}\right)$ is reached and no drop-in resistance after the ultimate load in compression is reached. For the brittle bolt shear failure, the load-displacement relationship of Fig. 9(b) was adopted. This relationship exhibits a steeper drop in resistance after the ultimate load is reached in both tension and compression. In both cases, the initial stiffness $(k)$ of the connection spring was estimated based on the Eurocode 3 Part 8 [46].

All components that contribute to the deformation of the fin-plate connection, according to Eurocode 3 Part 8 [46], are: $i$ ) bolt bearing of fin-plate, $i$ ) bolt bearing of the beam web and iii) bolt shear, were considered.

For bolts in bearing and in shear, the stiffness coefficients are given by the Eqs. (4) and (5), respectively:

$$
\begin{aligned}
& k_{12}=\frac{24 n_{\mathrm{b}} k_{\mathrm{b}} k_{\mathrm{t}} d f_{\mathrm{u}}}{E} \\
& k_{11}=\frac{16 n_{\mathrm{b}} d^{2} f_{\mathrm{ub}}}{E d_{\mathrm{M} 16}}
\end{aligned}
$$

where $d_{\mathrm{M} 16}$ is the nominal diameter of an M16 bolt, $n_{\mathrm{b}}$ is the number of bolt-rows in shear and $k_{\mathrm{b}}$ and $k_{\mathrm{t}}$ are calculated according to the Eq. (6):

$$
k_{\mathrm{b}}=\min \left(0.25 \frac{e_{\mathrm{b}}}{d}+0.5 ; 0.25 \frac{p_{\mathrm{b}}}{d}+0.375 ; 2.5\right), k_{\mathrm{t}}=\min \left(1.5 \frac{t_{\mathrm{j}}}{d_{\mathrm{M} 16}} ; 2.5\right)
$$

where $e_{\mathrm{b}}$ is the distance from the bolt-row to the free edge of the plate in the direction of the load, $f_{\mathrm{u}}$ is the ultimate tensile strength of the bolts' material, $p_{\mathrm{b}}$ is the spacing of the bolt-rows in the direction of the load, $t_{\mathrm{j}}$ is the thickness of the considered component.

Fig. 10 shows the configuration of a single bolt connection and its representation by a system of three springs in series. The equivalent spring is characterized by a stiffness $k_{\text {eq }}$ calculated by the following equation:

$$
\frac{1}{k_{\mathrm{eq}}}=\frac{1}{E_{\mathrm{b}} k_{11}}+\frac{1}{E_{\mathrm{fp}} k_{12, \mathrm{fp}}}+\frac{1}{E_{\mathrm{bw}} k_{12, \mathrm{bw}}}
$$

where $k_{12, \mathrm{fp}}$ and $k_{12, \mathrm{bw}}$ are the stiffness coefficients of the fin-plate and beam against bearing respectively, $k_{11}$ is the stiffness coefficients of the bolt against shear and $E_{\mathrm{b}}, E_{\mathrm{fp}}, E_{\mathrm{bw}}$ are the Young's modulus for the bolt, fin-plate and beam web respectively. 
The resistance of the equivalent spring is the minimum resistances among the three components. The eccentricity between fin-plate and beam web is negligible.

The strength resistances considered in [54] which were based on AISC regulations [55] for bearing failure at bolt holes and bolt shear failure are given in Table 4 .

\subsection{Modelling of the imperfections}

Lateral-torsional buckling was captured by including the initial geometrical imperfection in the model. This type of failure was expected only in the internal gravitational columns with cross-section HEB280 and hence, it was modelled only on these components of the Models 2 and 3 . The external columns had larger cross-sections and smaller axial loads and thus there was no need for the implementation of the imperfections.

The internal columns were modelled with the shape of an arch in the weak axis, so that buckling would be triggered in this direction. The amplitude of the imperfection was chosen such as the buckling to take place with a load similar to the Eurocode 3 [57] prediction for lateral-torsional buckling.

\subsection{Materials}

\subsubsection{Steel}

All steel components were modelled with an elasto-plastic stress-strain law as reported in Fig. 11. Typical values for the elastic properties e.g., Young's modulus $E$ and Poisson ratio $v$, and for the plastic properties e.g., yield strength $f_{\mathrm{y}}$, ultimate tensile stress $f_{\mathrm{u}}$, yield strain $\varepsilon_{\mathrm{y}}$ and the strain at the ultimate tensile stress point $\varepsilon_{\mathrm{u}}$, strain hardening ratio $\beta$, of the steel material are given in Table 1. For the stainless-steel duplex material of the WHPs, the hardening branch is based on coupon tests, while in all other cases, it is assumed linear.

\subsubsection{Concrete}

The concrete was modelled using the 'concrete damage plasticity' model in ABAQUS [45]. This model provides a general capability for modelling plain and reinforced concrete under monotonic, cyclic, and dynamic loading. It uses concepts of isotropic damaged elasticity in combination with isotropic tensile and compressive plasticity to represent the inelastic behavior of concrete. The concrete stress-strain curve in compression follows the modified Hognestad stress-strain relationship [49]. In this model, concrete Young's modulus $E_{\mathrm{c}}$ is taken as:

$$
E_{\mathrm{c}}=22\left(f_{\mathrm{c}} / 10\right)^{0.3}
$$

where $f_{\mathrm{c}}$ is the concrete compressive strength. Concrete is assumed to be in the elastic range for stresses up to $0.40 f$. The non-linear stress-strain relationship in compression is described by Eq. (9) according to a modified Hognestad relationship: 
$\sigma_{\mathrm{c}}=\left\{\begin{array}{c}E_{\mathrm{c}} \varepsilon_{\mathrm{c}}, \sigma_{c} \leq 0.4 f_{\mathrm{c}} \\ f_{\mathrm{c}}\left[2\left(\varepsilon_{\mathrm{c}} / \varepsilon_{0}\right)-\left(\varepsilon_{\mathrm{c}} / \varepsilon_{0}\right)^{2}\right], \sigma_{\mathrm{c}}>0.4 f_{\mathrm{c}}\end{array}\right.$

where for strength classes smaller than $\mathrm{C} 50 / 60$, the mean tensile strength $f_{\mathrm{ctm}}$ is related to the characteristic compressive strength $f_{\mathrm{ck}}$ and the mean compressive strength $f_{\mathrm{cm}}$ according to the relation:

$$
f_{\mathrm{ctm}}=0.30\left(f_{\mathrm{ck}}\right)^{0.3}=0.30\left(f_{\mathrm{cm}}-8\right)^{0.3}
$$

Strain softening after the peak stress was considered in the stress-strain curve with the slope of the descending softening equal to:

$$
K_{\mathrm{d}}=\frac{0.15 f_{\mathrm{c}}}{0.0038-\varepsilon_{0}}
$$

The ultimate strain considered in the analysis is equal to 0.009 . The plastic strain and stress are obtained by the following equations:

$\varepsilon_{\mathrm{p}}=\varepsilon-0.45 f_{\mathrm{c}} / E_{\mathrm{c}}, \sigma_{p}=\left[2\left(\varepsilon / \varepsilon_{0}\right)-\left(\varepsilon / \varepsilon_{0}\right)^{2}\right], \varepsilon_{y} \leq \varepsilon \leq \varepsilon_{c}$

The plastic strain-stress curve for the concrete in compression is reported in Fig. 12(a).

In tension, concrete behave elastically up to the ultimate tension stress $f_{\mathrm{t}}$. This point is followed by a softening branch. Two types of softening branches are considered: $i$ ) a 'realistic' softening branch and ii) a 'fictitious' softening branch as in Fig. 12(b). The use of the 'realistic' softening branch should be preferred for the simulation of the composite beam's behavior, however, while using the static general solver of ABAQUS, this leads to convergence problems. To overcome these problems, an explicit dynamic analysis must be performed, or, as an alternative, a 'fictitious' softening behavior can be adopted within a general static analysis. The 'fictitious' branch adopted in this paper was characterized by a linear descending behavior with a small softening. This was achieved by considering that the tensile strength reaches a tensile strength of $0.10 f_{\mathrm{t}}$ at a large strain equal to 0.05 . In the following sections, the consequences of using either of these two softening behaviors in the response of a composite beam is shown and comparisons are made with experimental results.

\section{VALIDATION OF THE NUMERICAL MODEL}

\subsection{Detailed and simplified WHPs models}

The effectiveness of the simplified WHPs' models in representing the structural response under the column loss scenario is evaluated in this section. The loss of column A3 (as in Fig. 1) was simulated on two equivalent 'Planar frame' models (Model 1) including the detailed and the simplified WHPs' models respectively. A linearly increasing displacement is imposed on the column and the required force monitored. The results of the force-displacements curves are reported in Fig. 13. The horizontal axis represents the 'push-down' displacement that is applied to the interior column while the vertical axis represents the corresponding 
reaction force. Fig. 13(a) and (b) correspond to the case where the PT bars are included or not, respectively. In the case without PT bars, the points of rotation of the beams is constrained to the column flanges. Fig. 13 shows a very good match of the results allowing the use of the simplified WHPs model. This model was used to derive the final results described in the following parts of the paper.

\subsection{Composite beams}

The accuracy of the modelling assumptions of the composite floor was assessed using experimental results reported in literature for two composite beams under both sagging and hogging bending $[52,53]$ named respectively composite beam 1 and 2 (i.e., CB1 and CB2). Composite beam reproducing the aforementioned tests were modelled using the techniques previously described for composite action. The mechanical idealization of the composite beam is reported in Fig. 14. Geometric and material non-linear behaviors were considered in the model.

The two experimental specimens of [52] and [53] have the same geometry as reported in Fig. 15 and Table 2 while their materials' properties are obtained by coupon tests and are given in Table 3. The slabs' reinforcement is comprised by longitudinal and transverse $12 \mathrm{~mm}$ rebars at the top of the slab only. A single row of shear studs with diameter of $19 \mathrm{~mm}$ is used for both the experimental studies. The exact positioning of the shear studs and the rebars is given in Fig. 15.

Fig. 16 gives the results from the numerical analyses for the two bending moment scenarios, i.e., sagging and hogging. In the case of sagging moments, the simplified numerical model predicts in an efficient way the complete load-displacement path. In the hogging moments, the numerical model exhibits a slightly larger stiffness and higher strength. These differences are due to the 'fictitious' constitutive law that is assumed for the concrete in tension (see Fig. 12(b)). The difference between the peak forces (at $46 \mathrm{~mm}$ displacement) is equal to $13.4 \%$, while the difference between the forces at the maximum displacement (approximately 100 $\mathrm{mm}$ ) is equal to 3.8. The differences between the numerical and experimental results are considered reasonably small and this model was used to derive the final results described in the following parts of the paper.

\subsection{Fin-plate connections}

Thompson [56] tested two-span beam assemblies with single fin-plate connections under the configuration illustrated in Fig. 17. A fairly short beam with a chord length of $L=1.89 \mathrm{~m}$ was used in these tests, where the chord length $L$ denotes the horizontal distance between bolt centerlines. Three different connection sizes were considered, having three, four, and five bolts per connection. The bolt diameter, plate thickness, and other properties shown in Fig. 18(a) were the same for all connection sizes, except for the plate depth that was 229,305 , and $381 \mathrm{~mm}$ for the three-, four-, and five-bolt connections, respectively. In all cases the center of the top bolt was located $76.2 \mathrm{~mm}$ below the top of the beam. Three tests for each connection size were conducted for a total of nine tests. The same beams were used in all tests, with 
doubler plates welded to the beam webs in the connection regions to prevent bearing induced deformations around the bolt holes in the beam web.

Fig. 18(b) shows the reduced modelling approach for the fin-plate connections. Each bolt row is represented by a nonlinear spring with properties depending on whether the failure is related to the bolt in shear or the bolt hole in bearing. The same spring properties were assumed for both the horizontal and vertical directions in an uncoupled manner.

Fig. 19 shows the force-displacement curve obtained by the numerical simulation adopting the reduced model of Fig. 18(b). In the same figure the results from the three experimental tests are given. The model can capture the true behavior at large displacements, makes a good estimation of the failure load and corresponding displacement and manages to capture the sudden drop of strength after the bolt failure.

The experimental response of the assemblies [Error! Reference source not found.] is composed by the following stages: (1) connection slippage, in which both the vertical load and the beam axial forces remain small before bolt bearing is engaged; (2) flexural action, in which the vertical load increases due to the development of bending moments in the singleplate shear connections, whereas the axial forces remain small; and (3) catenary action, in which tensile forces develop in the beams, accompanied by further increases in the vertical load until failure occurs. Bolt slippage cannot be captured by the connector elements used in the simplified model, thus the initial response of the numerical method is stiffer than the experimental one. However, the model can capture the true behavior at large displacements (the last two stages), makes a good estimation of the failure load and corresponding displacement and manages to capture the sudden drop of strength after the bolt failure. 3D modeling of bolts that could result in a better numerical response in the first stage was not an option, not only due to large number of connections existing in the model and the high computational cost and convergence problems that are associated with, but also to the fact that this would have a negligible impact on the response of the building as a much lower stiffness-strength element.

\subsection{PT connections}

The numerical model for the PT connections used in Vasdravellis et al. (2013) [48] is adopted in this paper. This model was previously validated against the experimental results of a cyclic test of a beam-column self-centering connection with PT bars subjected to large drifts up to $10 \%$. The comparison demonstrated a good agreement between the experimental and the numerical results. Therefore, the FEM modelling technique was considered reliable for the simulation of SC-MRFs under the column loss scenario.

\section{PROGRESSIVE COLLAPSE SIMULATION APPROACHES}

To study the robustness of the building against a sudden column loss, two different simulation approaches, each serving different objectives, were employed. 
First, a static 'push-down' analysis was employed and is performed on Model 1, 2 and 3. In this case, the 'removed' column was pushed down up to a large displacement corresponding to connection rotations larger than $0.2 \mathrm{rad}$. This analysis allowed to identify all possible failure modes of the frame. Moreover, it is used to quantify the contribution, on the progressive collapse resistance, of the frame continuity in the orthogonal direction and of the floor system by the development of 3D membrane actions. In these analyses, the quasi-static option of the implicit dynamic solver of ABAQUS was employed, since it allows to overcome many of the convergence problems associated with the sharp drop in strength due to brittle failures, such as the fracture of WHPs.

The 'push-down' analysis consisted of three steps: 1) application of an initial post-tensioning force of $1087 \mathrm{kN}$ in the PT bars of the SC-MRFs. In the 3D models, the post-tensioning in the SC-MRF placed in D25 (see Fig. 1(a)), far from the collapsing column and modelled by 'frame' elements, is simulated by two concentrated forces in the beam-column connections D2 and D5 (see Fig. 1(a)); 2) application of the upper story gravity load at all the columns, except the column A3 where the collapse is simulated. The load is applied as concentrated force in the columns top and is calculated according to the load combination of the UFC [19] (i.e., 1.2DL+0.5LL); and 3) removal of the support and imposition of a linear variation of the displacement in the vertical direction at the top of the column A3.

The second simulation approach is used only on the Model 3 (3D frame with slab). This analysis served to assess the safety factor of the building against the accidental load combination prescribed in the UFC regulations [19], and to estimate the DIF to be used with nonlinear static analyses. For the estimation of the DIF, both nonlinear quasi-static and dynamic analyses have been performed.

In the static analysis, the load combination of the UFC [19] is increased in a linear fashion by a factor $\lambda$. The load is applied as a pressure acting on the slab and as concentrated force on top of the first story columns to account for the upper story gravity load. The steps of the quasi-static numerical analysis were: 1) application of the initial post-tensioning force in the PT bars; 2) removal of the support of column A3 and application of the load $\lambda(1.2 \mathrm{DL}+0.5 \mathrm{LL})$ with the factor $\lambda$ that increases linearly until collapse is observed. The analysis provides information on the load intensity-displacement $(\lambda-U)$ curve, together with the sequence of failure modes and the maximum load intensity the structure is able to sustain before the progressive collapse takes place.

Differently, the dynamic analysis involved the following three steps: 1) application of the initial post-tensioning force in the PT bars; 2) application of the gravity loads, according to the load combination $\lambda(1.2 \mathrm{DL}+0.5 \mathrm{LL})$, for a given value of the $\lambda$ factor; 3 ) sudden removal of the column A3 support. The implicit dynamic solver with the moderate dissipation option is used to capture the dynamic behavior of the structure. This solver is suitable for problems including contact interaction phenomena.

Explicit algorithms could be extremely helpful in avoiding many convergence problems that are typically encountered when using the implicit solution methods, especially in the near and post collapse region. However, huge computational resources should be available due to the large number of elements used in the analysis and the very small critical time step that the 
explicit method would require to be stable as a result of the small size of the elements. For this reason, a dynamic implicit solution scheme was preferred over the explicit one.

\section{RESULTS AND DISCUSSION}

\section{1 'Push-down' analysis}

Fig. 20 shows the force versus vertical displacement at the 'removed' column as obtained from the 'push-down' analysis for the Models 1,2 and 3. The horizontal axis represents the vertical displacement of the column while the vertical axis shows the corresponding applied force. Models 1 and 2 produce an about identical force-displacement response, indicating that 3D actions of the steel components alone are negligible. Differently, the effect of the composite floor is significant and increases the overall resistance of the system of about $30 \%$.

The sequence of the most significant failures taking place during the 'push-down' of the A3 column in Model 3 is reported in Fig. 20. The sequence of failure modes is the following: $i$ ) first yielding of the WHPs (47 mm; $0.0064 \mathrm{rad})$; ii) first yielding of the fin-plate $(96 \mathrm{~mm}$; $0.0125 \mathrm{rad}$ ); iii) initiation of buckling of the SC-MRF beam after the stiffening web and flange plates (about $200 \mathrm{~mm} ; 0.026 \mathrm{rad}$ ); $i v$ ) first yielding of the shear studs (200 $\mathrm{mm} ; 0.026$ $\mathrm{rad}$ ); v) first yielding of the PT bars (about $0.733 \mathrm{~m} ; 0.0955 \mathrm{rad}$ ); vi) first fracture of the WHPs (about $1.35 \mathrm{~m} ; 0.1759 \mathrm{rad}$ ). The same sequence, with failures happening approximately for the same values of the displacements, is observed from Models 1 and 2. The buckling of the SC-MRF beam is responsible for the significant reduction of the system's stiffness (see Fig. 20), however, while the displacement increases, the catenary actions become more significant and at about $0.5 \mathrm{~m}$ displacement, the system become stiffer. After large rotations have taken place, the PT bars yield and the most stressed WHPs fracture. The WHPs' fracture corresponds to the sharp drops of strength observed in Fig. 20 for the three models.

Fig. 21, Fig. 22 and Fig. 23 show the deformed shapes at large column displacement together with the details of the self-centering beam column joint of the 'removed' column respectively for Models 1, 2 and 3. The local buckling causing the local flattening of the loaddisplacement curves of Fig. 20 is visible in these images and is located at the end of the beam A23 after the web and flange stiffeners.

The presence of the slab and the lateral beams restrict the lateral buckling of the SC-MRF beam, however, does not alter the basic in-plane non-uniform axial stress state of the beam which is responsible for the local buckling of the beam. The local buckling of the beam degrades drastically the initial bending stiffness of the beam at the point of local buckling and is responsible for the drastic reduction of the SC-MRF stiffness. The increase of resistance that is observed in the later stages is due to the catenary action of the PT bars.

Fig. 24 shows the evolution of PT bar stress versus the vertical displacement at the 'removed' column for the three models. The figure shows that the behavior is not affected by the $3 \mathrm{D}$ actions of the steel components nor by the slab. PT bars are deformed elastically until the column A3 displacement reaches a value of $733 \mathrm{~mm}$. After this displacement PT bars yields, however, no fracture is observed up to a column displacement equal to $2.0 \mathrm{~m}$. 
Fig. 25 shows the evolution of WHPs force versus the vertical displacement at the 'removed' column for the planar model (Model 1), however, the comparison shows that there is no difference between these results and the one of the 3D model without slab (Model 2). The WHPs forces in the beam-to-column connection A23, A32, A34 and A43 are given in Fig. 25 (a), (b), (c) and (d), respectively. Each WHP is named according to its position within the SCMRF (e.g., A23-WHP1 is the WHP connecting the beam A23 to the column A2 and is near to the top flange as in Fig. 2(c)). In the A23 and A43 connections only the top WHPs (i.e., A23WHP1\&2 and A43-WHP1\&2) reach the ultimate strength and fracture. In A32 connection although the WHPs exhibit large plastic deformation, none of them reaches the ultimate strength and thus they just yield but do not fracture. Differently, the bottom WHPs of the A34 connection (i.e., A34-WHP3\&4) are fractures while the top WHPs (i.e., A34-WHP1\&2) are yielded and are very close to their ultimate strength but they do not fracture. A32 and A34 are the connections of the 'removed' column A3. The differences between the behavior of WHPs of these two connections are related to the fact that the during collapse, the column is not displaced vertically only but rotates also such that WHPs in the A34 connection are more deformed than the A32 connection WHPs.

Fig. 26 shows the evolution of WHPs force versus the vertical displacement at the 'removed' column for the 3D model with slab (Model 3). The presence of slab influences the response of the WHPs in some cases compared to Models 1 and 2. More specifically, it protects the WHPs of the A23 connection from fracturing, delays the fractures in the WHPs of the A43 connection (e.g., $1.90 \mathrm{~m}$ instead of $1.54 \mathrm{~m}$ ) and increase the demand and fractures all the WHPs of the connection 34 .

Models 2 and 3 simulate also the failure modes associated with the beams in the orthogonal direction. Orthogonal beams near to the 'removed' column are in fact affected by the large displacements and plastic deformations are observed in their fin-plate connections. Three finplate typologies are used within the building. Fin-plates of the secondary and primary beams use respectively three and five bolts as described in Fig. 27. The reduced modelling approach for the fin-plate joints used nonlinear connectors, one for each bolt row in the connection, with distinct load-deformation curves to represent yielding and failure. All components that contribute to the deformation of the fin-plate connection were defined according to Eurocode 3 Part 8 [46] as discussed in Section 3.

The affected beams are the secondary beams G4 to G9 in the AB bay and the main beam AB3 as shown in Fig. 1. Each fin-plate's nonlinear connector is named according to its position within the structure (e.g., G4-AB-1 is the connector near to the top flange as in Fig. 27 (a) connecting the beams G4 to the beam in the frame A).

Fig. 28 provides the axial forces of each fin-plate connector for the G4, G5, G6 and AB3 beams for the Model 2. Beams G7, G8 and G9 are not reported being similar to the previous one due to symmetry with respect to the 'removed' column. Fig. 28 shows that the nonlinear connectors of the fin-plates closer to the column A3 undergo larger plastic deformations, moreover, yielding is reached for lower displacements. The nonlinear connectors of the finplates of beam AB3 exhibit very large plastic deformations as reported in Fig. 28(d). Some fractures are observed at the connection with column B3. 
Fig. 29 provides the same information for the Model 3. Also in this case, the plastic deformations in the fin-plate connectors of the beam AB3 are significant leading to fractures at large displacements. Differently from Model 2, it is possible to observe the effect of the composite slab in the connections. In fact, all the connectors of the fin-plates connecting the secondary beams with the primary beam in B yield due to compression forces. In addition, as clearly illustrated in Fig. 29(c), after yielding, a reduction of the compression force is observed corresponding to a displacement of $0.5 \mathrm{~m}$ and due to the development of catenary forces.

Fig. 30 shows the evolution of the plastic energy for all the structural components. The most significant plastic energy is developed mostly in the PT bars, in the WHPs and in the slabs. In a smaller degree also in the SC-MRF and in the fin-plate connections while the shear studs have a negligible plastic energy. Fig. 31 shows the extend of plastic deformation in the slabs corresponding to a vertical displacement of the column A3 of $2 \mathrm{~m}$. Only the slab near the 'removed' column is damaged.

\subsection{Dynamic Increase Factor (DIF)}

This section evaluates the DIF to be used within nonlinear static analyses while simulating the progressive collapse of building structures. All the analyses are performed for the 3D Model with slab only (Model 3) and by following the second simulation approach described in Section 5. The load intensity-displacement $(\lambda-U)$ curves are derived from quasi-static and dynamic analyses and their comparison provides useful information to estimate the DIF.

The $\lambda$-U curve from the quasi-static analysis is shown in Fig. 32(a). In the same figure, the sequence of failures that take place as the load intensity increases is shown. This includes the initial yielding taking place in different parts of the structure, e.g., fin-plate connections, WHPs, gravity columns, gravity beams, beams and columns of the SC-MRF and the buckling of column B3. The load intensity reaches its maximum, before collapse is observed, for a $\lambda$ equal about to 2.05. The collapse condition is related to the buckling of column B3 as shown in Fig. 33. Apart from the B3 column buckling all the failures observed are of secondary importance and do not jeopardize the integrity of the structure.

After the column buckling, the four beam-column connections of column B3 plus the finplate connection that supports the main beam AB3 to the SC-MRF, are subjected to high deformations leading to fracture. These connection failures lead to a loss of vertical stiffness and, as the applied load 'searches' for alternative load paths, the A3 column shows a $20 \mathrm{~mm}$ backwards displacement before starting to deform in the gravity direction again as shown in the Fig. 32(b). Due to convergence problems, the behavior of the structure beyond that point could not be simulated.

Fig. 34 provides the axial force for the connectors of the fin-plate connecting the beam B23 to the column B3. Each fin-plate's nonlinear connector is named according to its position within the structure (e.g., B23-3-1 is the connector near to the top flange as in Fig. 27(a) connecting the beams B23 to the column in the frame 3). In the step 1 of the analysis, the PT bars post-tensioning force induces a compression of the fin-plate's connectors (see Fig. 34). 
In the step 2, the column A3 is 'removed' and the load linearly increased. Due to the interaction with the slab, the fin-plate has the center of rotation at the level of the second connector (B23-3-2) where the force remains about constant. When the column B3 buckles, at a time of about $8 \mathrm{sec}$, a sudden pull-out force is applied to all the connectors, but this seize instantly and the beam B23 start compressing the fin-plate immediately after. The only connectors experiencing plastic deformations before the column buckling is the connector B23-3-5.

Fig. 35 shows the displacement time histories of the 'removed' column A3 for different values of the load intensity factor $\lambda$. The maximum load intensity that the structure can sustain is equal to 2.17. Beyond this load the structure becomes unstable and excessive displacements appear. However, note that the failure that signifies the progressive collapse of the building is the buckling of the neighboring column B3. From the nonlinear analyses, the dynamic curve reported in Fig. 36(a) can be constructed in the following way. For each load intensity $\lambda, 0 \leq \lambda \leq \lambda_{\max }$ where $\lambda_{\max }$ is the maximum load intensity the structure can sustain (in this case 2.17), the maximum attained displacement during the vibration is recorded. For the case of $\lambda_{\max }$ the maximum displacement estimated at the end of the analysis is being used. By plotting the pairs of maximum displacements and the corresponding load intensities the dynamic curve can be derived. In Fig. 36(a) the $\lambda$-U curves obtained from the quasi-static and dynamic analyses are reported. The DIF can be derived in two different ways [58] as follow:

1. Based on the displacements obtained from the two analysis methods $\left(\mathrm{DIF}_{\mathrm{U}}\right)$

$$
\mathrm{DIF}_{\mathrm{U}}=\frac{U_{\text {Dyn }}}{U_{\text {Stat }}}
$$

2. Based on the load intensity factors obtained from the two analysis methods $\left(\mathrm{DIF}_{\mathrm{F}}\right)$

$$
\mathrm{DIF}_{\mathrm{F}}=\frac{\lambda_{\text {Stat }}}{\lambda_{\text {Dyn }}}
$$

In Eq. (13), $U_{\text {Dyn }}$ and $U_{\text {Stat }}$ are the dynamic and static displacements respectively for a given load intensity factor $\lambda$. On the other hand, in Eq. (14), if $\lambda_{\text {Stat }}$ and $U_{\text {Stat }}$ are the load intensity factor and displacement at a given point of the $\lambda$-U curve, then $\lambda_{\text {Dyn }}$ is the load intensity factor of dynamic force-displacement curve that corresponds to the displacement $U_{\text {Stat }}$. The estimated DIF, DIF $\mathrm{U}_{\mathrm{U}}$ and $\mathrm{DIF}_{\mathrm{F}}$, from both the displacements and the load intensity factors are shown in Fig. 36(b). The $\mathrm{DIF}_{\mathrm{F}}$ is approximately equal to $\mathrm{DIF}_{\mathrm{U}}$ for $\lambda<0.80$, while for larger values the $\mathrm{DIF}_{\mathrm{F}}$ is smaller. For $\lambda=1.0$ the $\mathrm{DIF}_{\mathrm{F}}$ is equal to 1.754 and the $\mathrm{DIF}_{\mathrm{U}}$ equal to 1.90 . for $\lambda>1.20$, the $\mathrm{DIF}_{\mathrm{F}}$ and $\mathrm{DIF}_{\mathrm{U}}$ stabilize approximately to an average value of 1.64 and 2.16, respectively.

\subsection{Effect of 'weak columns'}

In the previous section it has been shown that progressive collapse in the steel building is initiated due to the buckling of the column B3 which is next to column A3. Have the internal columns been stronger the building would have been able to sustain a larger load intensity 
before failure. In this section, an investigation is made to estimate this maximum load intensity factor when the columns are protected from buckling. To achieve this, all the columns of the building are restrained with boundary conditions in the two orthogonal directions $(\mathrm{X}, \mathrm{Y})$. The quasi-static analysis method with $\lambda$ factor linear increasing is used.

Fig. 37 shows the $\lambda$-U curves obtained from the quasi-static analysis with and without the column restraints. The maximum load intensity factor when the column buckling is prevented is equal to 3.17 and the collapse is related to the failure of a fin-plate connection. The $\lambda$ factor achieved when column buckling in not prevented is equal to 2.05 and hence, the load intensity factor in the case we take measures to prevent column buckling, e.g., by increasing the columns' cross-section, is increased by $35 \%$.

Fig. 38 shows two failure modes that appear at the maximum estimated load intensity factor $\lambda$ for the building with column restraints. Fig. 38(a) shows the vertical displacement of the edge of the beam B32 connected by the fin-plate to column B3 with respect to the factor $\lambda$. When the load intensity factor reaches the value of 3.15 , the beam end shows a large vertical drop which is due to the shear force reaching the shear resistance of the fin-plate connection. This failure poses convergence problems and do not allow the analysis to estimate the post-failure behavior. Considering the tributary area for each connection and the maximum load intensity factor $(\lambda=3.17)$, the shear load for each of the five bolts of the fin-plate connection is equal to $95 \mathrm{kN}$. This value is very close to the ultimate strength in bearing for each of the bolts of the fin-plate connections. Thus, simple calculation justifies the validity of the numerical analysis predictions. The second failure mode is related to the local buckling in the two beams of the SC-MRF that connected to the 'removed' column (as reported in Fig. 38(b)), however, this failure mode do not affect the progressive collapse resistance of the building.

\section{CONCLUSIONS}

In this paper, the robustness of a steel building with self-centering moment resisting frames (SC-MRFs) is examined numerically via nonlinear quasi-static and dynamic analyses. Only the first floor of the building is modelled and studied against a sudden column removal scenario. Simplified and detailed numerical models are developed and validated against past experimental results for all the basic components of the building i.e., the composite floor, the SC-MRF and the fin-plate connections. Of great interest is the effect of the composite floor on the robustness of the building. For this purpose, three numerical models are developed, namely, the planar model, containing the SC-MRF only, the 3D model, where all the structural components were modelled except the slab and the 3D model with the slab.

The most important conclusions from this study can be summarized as follows:

- It is found that the frame model without slab and the planar model have the same behavior, thus the fin-plate connections that connect the frame elements to the SCMRF are very weak to increase stiffness or strength;

- Under the 'push-down' analysis method, the model with slab shows larger stiffness and strength that is approximately $30 \%$ higher with respect to the other two models. 
This reveal a significant contribution of the composite floor to the robustness of the building;

- Using the more realistic nonlinear dynamic analyses, it is found that the building can sustain 2.05 times the gravity loads of the load combination proposed by the Unified Facilities Criteria (UFC);

- Performing quasi-static analyses by gradually increasing the UFC load combination loads, the evolution of all failure modes from minor (i.e., no leading to collapse) to major (i.e., leading to collapse) have been evaluated. Initially, a series of minor failures are traced in the load-displacement curve. Then with a load intensity factor $(\lambda)$ equal to 2.05 a column buckling takes place, characterized by a complex snapback behavior that signifies the ultimate resistance of the building;

- Dynamic Increase Factor (DIF) values are estimated based on displacements and forces. It is found that both DIFs are equal for values of $\lambda$ up to 0.80 . For higher $\lambda$ values the $\mathrm{DIF}_{\mathrm{F}}$ and $\mathrm{DIF}_{\mathrm{U}}$ stabilize approximately to average values of 1.64 and 2.16, respectively;

- The estimated DIFs can be used for assessing the progressive collapse resistance of SCMRF using nonlinear static analysis instead of a dynamic one.

- Since column buckling governed the ultimate collapse resistance of the building, a second quasi-static analysis is performed to investigate the maximum collapse resistance the building can reach if column buckling is prevented. This is of interest to extend the achieved results to other case studies where the columns may be bigger. It is concluded that when columns' buckling is not the predominant failure mode, the building can sustain 3.17 times at most the UFC load combination. In this case the failure mode is located in the four fin-plate connections of the internal column next the 'removed' one.

- Based on the outcomes of this research it can be expected that steel buildings with PT connections designed to accommodate seismic events with PGA larger than $0.35 \mathrm{~g}$ and typical Type B soil conditions according to eurocode 8 will be robust enough to survive in the case of an internal column removal of the SC-MRF.

\section{ACKNOWLEDGEMENTS}

This research is supported by Marie Sklodowska-Curie Action Fellowships within the H2020 European Programme. Any opinions, findings, and conclusions or recommendations expressed in this paper are those of the authors and do not necessarily reflect the views of the European Commission.

\section{REFERENCES}

1. EN 1998-1. Eurocode 8: Design of structures for earthquake resistance. Part 1: General rules, seismic action and rules for buildings. European Standard EN 1998-1. European Committee for Standardization 
(CEN), 2005, Brussels, Belgium.

2. Federal Emergency Management Agency. FEMA 350. Recommended seismic design criteria for new steel moment-frame buildings. SAC Joint Venture 2000, Washington, DC.

3. Garlock M, Sause R, Ricles JM. Behavior and design of posttensioned steel frame systems. Journal of Structural Engineering 2007; 133(3): 389-399.

4. Dimopoulos AI, Karavasilis TL, Vasdravellis G, Uy B. Seismic design, modelling and assessment of self-centering steel frames using post-tensioned connections with web hourglass shape pins. Bulletin of Earthquake Engineering 2013; 11(5): 1797-1816.

5. Tzimas AS, Dimopoulos AI, Karavasilis TL. EC8-based seismic design and assessment of selfcentering post-tensioned steel frames with viscous dampers. Journal of Constructional Steel Research 2015; 105: $60-73$.

6. Dimopoulos AI, Tzimas AS, Karavasilis TL, Vamvatsikos. Probabilistic economic seismic loss estimation in steel buildings using post-tensioned moment-resisting frames and viscous dampers. Earthquake Engineering \& Structural Dynamics 2016; 45(11): 1725-1741.

7. Tzimas AS, Kamaris GS, Karavasilis TL, Galasso C. Collapse risk and residual drift performance of steel buildings using post-tensioned MRFs and viscous dampers in near-fault regions. Bulletin of Earthquake Engineering 2016; 14(6): 1643-1662.

8. Freddi F, Dimopoulos CA, Karavasilis TL. Rocking damage-free steel column base with friction devices: design procedure and numerical evaluation. Earthquake Engineering \& Structural Dynamics 2017; 46(14): 2281-2300.

9. Li Y, Ahuja A, Padgett JE. Review of methods to assess, design for, and mitigate multiple hazards. Journal of Performance of Constructed Facilities 2012; 26(1): 104-117.

10. Barbato M, Palmieri A, Petrini F. Special Issue on Performance-based engineering. Engineering Structures 2014; 78: 1-2.

11. Adam, JM, Parisi F, Sagaseta J, Lu X. Research and practice on progressive collapse and robustness of building structures in the $21^{\text {st }}$ century. Engineering Structures 2018; 173: 122-149.

12. EN 1991-1-7. Eurocode 1: Actions on structures - Part 1-7: General actions - Accidental actions. European Standard EN 1991-1-7. European Committee for Standardization (CEN), 2006, Brussels, Belgium.

13. Pearson C, Delatte N. Ronan Point apartment tower collapse and its effect on building codes. Journal of Performance of Constructed Facilities 2005; 19(2): 172-177.

14. Sozen MA, Thornton CH, Corley WG, Mlakar PF. The Oklahoma city bombing: Structure and mechanisms of the Murrah Building. Journal of Performance of Constructed Facilities 1998; 12(3): 120136.

15. Bažant ZP, Verdure M. Mechanics of progressive collapse: Learning from World Trade Center and building demolitions. Journal of Engineering Mechanics 2007; 133(3): 308-319.

16. Ellingwood BR. Mitigating risk from abnormal loads and progressive collapse. Journal of Performance of Constructed Facilities 2006; 20(4): 004604QCF: 315-323.

17. Izzuddin BA, Vlassis AG, Elghazouli AY, Nethercot DA. Progressive collapse of multi-storey buildings due to sudden column loss - Part I: Simplified assessment framework. Engineering Structures 2007; 30: 1308-1318.

18. Vlassis AG, Izzuddin BA, Elghazouli AY, Nethercot DA. Progressive collapse of multi-storey buildings due to sudden column loss - Part II: Application. Engineering Structures 2007; 30: 1424-1438.

19. DoD. Unified Facilities Criteria (UFC) - Design of structures to resist progressive collapse. 4-023- 
0314, July 2009 - Change 3, 1 November 2016. United States Department of Defense (DoD).

20. GSA. Progressive collapse analysis and design guidelines for new federal office buildings and major modernization projects. General Services Administration, 2003, Washington, DC.

21. Demonceau JF, Jaspart JP. Experimental test simulating a column loss in a composite frame. Advanced Steel Construction 2010; 6(3): 891-913.

22. Yang B, Tan KH. Experimental tests of different types of bolted steel beam column joints under a central-column-removal scenario. Engineering Structures 2013; 54: 112-30.

23. Wang W, Wang J, Sun X, Bao Y. Slab effect of composite subassemblies under a column removal scenario. Journal of Constructional Steel Research 2017; 129: 141-155.

24. Dinu F, Marginean I, Dubina D, Petran I. Experimental testing and numerical analysis of 3D steel frame system under column loss. Engineering Structures 2016; 113: 59-70.

25. Zandonini R, Baldassino N, Freddi F, Roverso G. Steel-Concrete Composite Frames under the Column Loss Scenario: an Experimental Study. Journal of Constructional Steel Research 2019.

26. Jahromi HZ, Izzuddin BA, Nethercot DA, Donahue S, Hadjioannou M, Williamson EB, Engelhardt M, Stevens D, Marchand K, Waggoner M. Robustness assessment of building structures under explosion. Buildings 2012; 2(4), 497-518.

27. ASCE/SEI 7-10. Minimum design loads for buildings and other structures. American Society of Civil Engineers 2010, Reston, VA.

28. Johnson ES, Meissner JE, Fahnestock LA. Experimental Behavior of a Half-Scale Steel Concrete Composite Floor System Subjected to Column Removal Scenarios. Journal of Structural Engineering (ASCE) 2016; 142(2): 04015133: 1-12.

29. Song BI, Giriunas KA, Sezen H. Progressive collapse testing and analysis of a steel frame building. Journal of Constructional Steel Research 2014; 94: 76-83.

30. El-Tawil S, Li H, Kunnath S. Computational Simulation of Gravity-Induced Progressive Collapse of Steel-Frame Buildings: Current Trends and Future Research Needs. Journal of Structural Engineering (United States) 2014; 140(8): A2513001: 1-12.

31. Sadek F, El-Tawil S, Lew H. Robustness of composite floor systems with shear connections: modeling, simulation, and evaluation. ASCE Journal of Structural Engineering 2008; 134: 1717-25.

32. Alashker Y, El-Tawil S, Sadek F. Progressive collapse resistance of steel-concrete composite floors. Journal of Structural Engineering (ASCE) 2010; 136:1187-96.

33. Olmati P, Petrini F, Bontempi F. Numerical analyses for the structural assessment of steel buildings under explosions. Structural Engineering and Mechanics 2013; 45(6): 803-819.

34. Main JA. Composite Floor Systems under Column Loss: Collapse Resistance and Tie Force Requirements. Journal of Structural Engineering (ASCE) 2014; 140(8): A4014003: 1-15.

35. Jahromi HZ, Vlassis AG, Izzuddin BA. Modelling approaches for robustness assessment of multistorey steel-composite buildings. Engineering Structures 2013; 51: 278-294.

36. Li H, El-Tawil S. Three-dimensional effects and collapse resistance mechanisms in steel frame buildings. Journal of Structural Engineering (United States) 2014; 140(8): A4014017: 1-11.

37. Tsitos A, Mosqueda G. Experimental investigation of the progressive collapse of a steel special moment-resisting frame and a post-tensioned energy dissipating frame. In: Fardis MN, Rakicevic ZT, editors. Role of seismic testing facilities in performance-based earthquake engineering. Geotechnical, geological, and earthquake engineering, Springer, 2011; 22: 367-82.

38. Pirmoz A, Liu M. Finite element modeling and capacity analysis of post-tensioned steel frames against progressive collapse. Engineering Structures 2016; 126: 446-456. 
39. Vasdravellis G, Baiguera M, Al-Sammaraie D. Robustness assessment of a steel self-centering moment-resisting frame under column loss, Journal of Constructional Steel Research 2018; 141: 36-49.

40. Ghorbanzadeh, B., Bregoli, G., Vasdravellis, G., Karavasilis, T.L. (2019) "Pilot experimental and numerical studies on a novel retrofit scheme for steel joints against progressive collapse". Engineering Structures, 200, art. no. 109667.

41. Baiguera M., Vasdravellis G., Karavasilis T.L. (2018). "Ultra-low cycle fatigue tests and fracture prediction models for duplex stainless-steel devices of high-performance braced frames". Journal of Structural Engineering (ASCE), 145(1).

42. Zandonini R, Freddi F, Baldassino N. Robustness of steel-concrete flooring systems - An experimental assessment. Stahlbau 2014; 83(9): 608-613.

43. Ding Y, Song X, Zhu HT. Probabilistic progressive collapse analysis of steel-concrete composite floor systems. Journal of Constructional Steel Research 2017; 129: 129-140.

44. EN1991-1-1. Eurocode 1: Actions on structures - Part 1-1: General actions - Densities, self-weight, imposed loads for buildings. European Standard EN 1991-1-1. European Committee for Standardization (CEN) 2006, Brussels, Belgium.

45. ABAQUS/Standard and ABAQUS/Explicit - Version 2016. ABAQUS Theory Manual, Dassault Systems, 2016.

46. EN1993-1-8. Eurocode 3: Design of steel structures - Part 1-8: Design of joints. European Standard EN 1993-1-8. European Committee for Standardization (CEN), 2003, Brussels, Belgium.

47. Vasdravellis G, Karavasilis TL, Uy B. Large-Scale Experimental Validation of Steel Posttensioned Connections with Web Hourglass Pins., Journal of Structural Engineering 2013; 139(6): 1033-1042.

48. Vasdravellis G, Karavasilis TL, Uy B. Finite element models and cyclic behavior of self-centering steel post-tensioned connections with web hourglass pins. Engineering Structures 2013; 52: 1-16.

49. Hognestad E. A study of combined bending and axial load in reinforced concrete members. Bull. Ser. No. 399, University of Illinois at Urbana-Campaign, College of Engineering, Engineering Experiment Station, Urbana, IL.

50. EN1994-1-1. Eurocode 4: Design of composite steel and concrete structures - Part 1-1: General rules and rules for buildings. European Standard EN 1994-1-1. European Committee for Standardization (CEN), 2004, Brussels, Belgium.

51. Prakash A, Anandavalli N, Madheswaran CK, Lakshmanan N. Modified Push-out Tests for Determining Shear Strength and Stiffness of HSS Stud Connector-Experimental Study. International Journal of Composite Materials 2012; 2(3): 22-31.

52. Vasdravellis G, Uy B, Tan EL, Kirkland B. The effects of axial tension on the sagging-moment regions of composite beams. Journal of Constructional Steel Research 2012; 72: 240-253.

53. Vasdravellis G, Uy B, Tan EL, Kirkland B. The effects of axial tension on the hogging-moment regions of composite beams. Journal of Constructional Steel Research 2012; 68: 20-33.

54. Main JA, Sadek F. Modeling and Analysis of Single-Plate Shear Connections under Column Loss. Journal of Structural Engineering 2014; 140(3): 04013070.

55. AISC. Specification for structural steel buildings. ANSI/AISC 360-10, Chicago, 2010.

56. Thompson SL. Axial, shear and moment interaction of single plate 'shear tab' connections. MS thesis, Milwaukee School of Engineering 2009, Milwaukee.

57. EN1993-1-1. Eurocode 3: Design of steel structures - Part 1-1: General rules and rules for buildings. European Standard EN 1993-1-1. European Committee for Standardization (CEN), 2005, Brussels, Belgium. 
58. Fu QN, Tan KH, Zhou XH, Yang B. Numerical simulations on three-dimensional composite structural systems against progressive collapse. Journal of Constructional Steel Research 2017, 135: 125-136. 


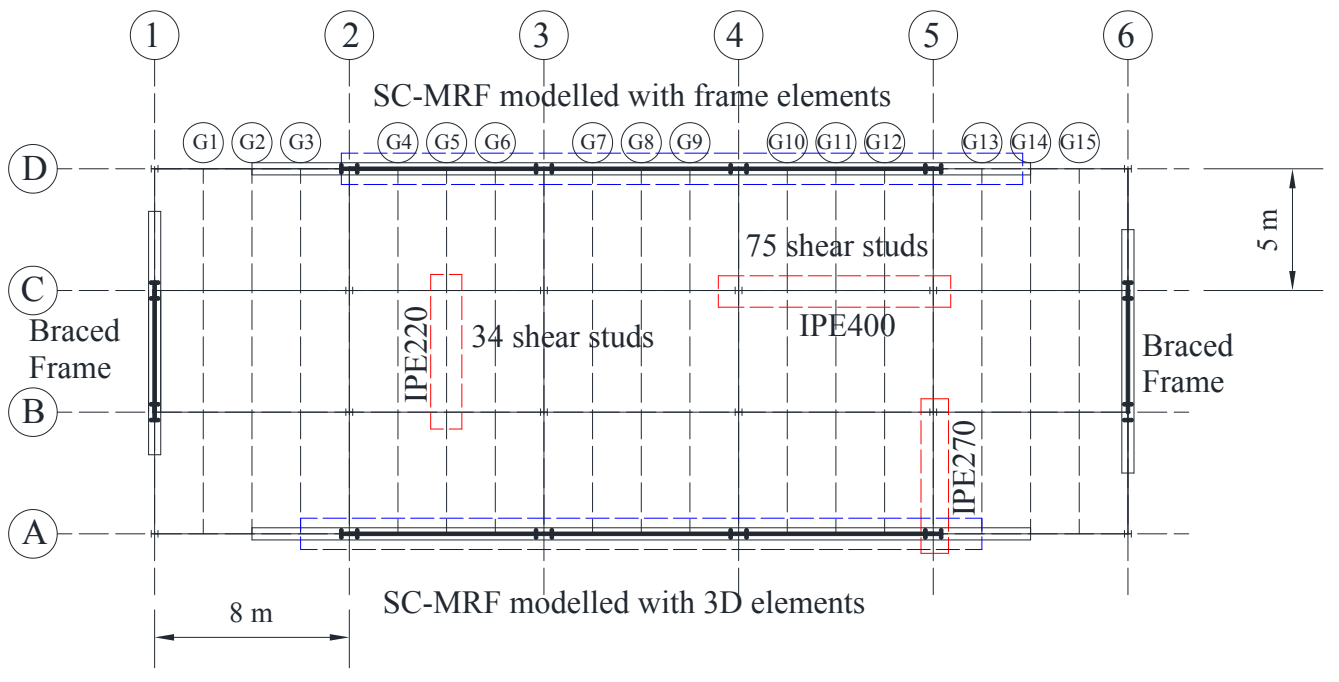

(a)

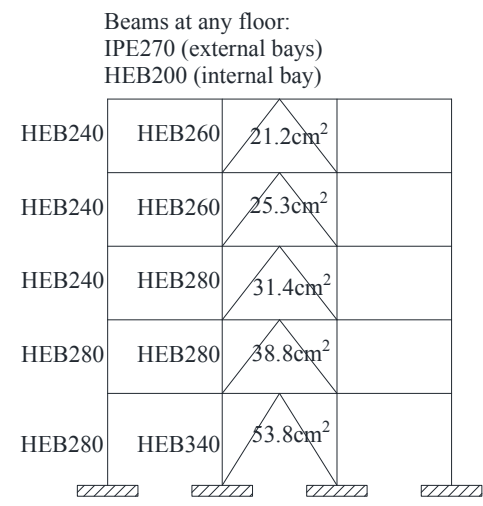

Frames $1 \& 6$

\begin{tabular}{|c|c|c|c|c|}
\hline & IPE400 & IPE400 & IPE400 & \\
\hline HEB240 & $\begin{array}{l}\text { HEB600 } \\
\text { IPE400 }\end{array}$ & $\begin{array}{l}\text { HEB600 } \\
\text { IPE400 } \\
\end{array}$ & IPE400 & ñ \\
\hline HEB240 & $\begin{array}{l}\text { HEB600 } \\
\text { IPE400 }\end{array}$ & $\begin{array}{l}\text { HEB600 } \\
\text { IPE450 } \\
\end{array}$ & IPE450 & ले. \\
\hline HEB 240 & $\begin{array}{l}\text { HEB650 } \\
\text { IPE400 }\end{array}$ & $\begin{array}{l}\text { HEB650 } \\
\text { IPE500 } \\
\end{array}$ & IPE500 & ले \\
\hline HEB 280 & $\begin{array}{l}\text { HEB650 } \\
\text { IPE400 }\end{array}$ & $\begin{array}{l}\text { HEB650 } \\
\text { IPE450 }\end{array}$ & IPE450 & ñ. \\
\hline HEB 280 & HEB650 & HEB650 & & + \\
\hline
\end{tabular}

Frames A \& D

(b)

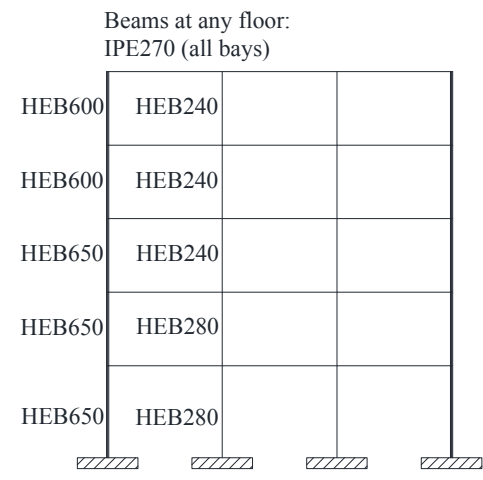

Frames 2 to 5

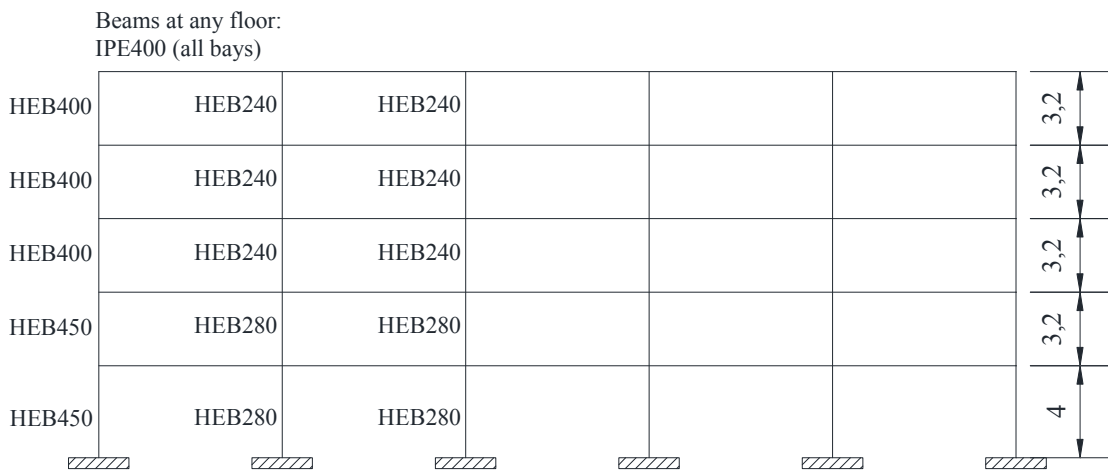

Frames B \& C

(c)

Fig. 1: Prototype building: (a) plan view; (b) elevation view of external frames; (c) elevation view of internal frames. (thicker lines denote members of SC-MRFs) 


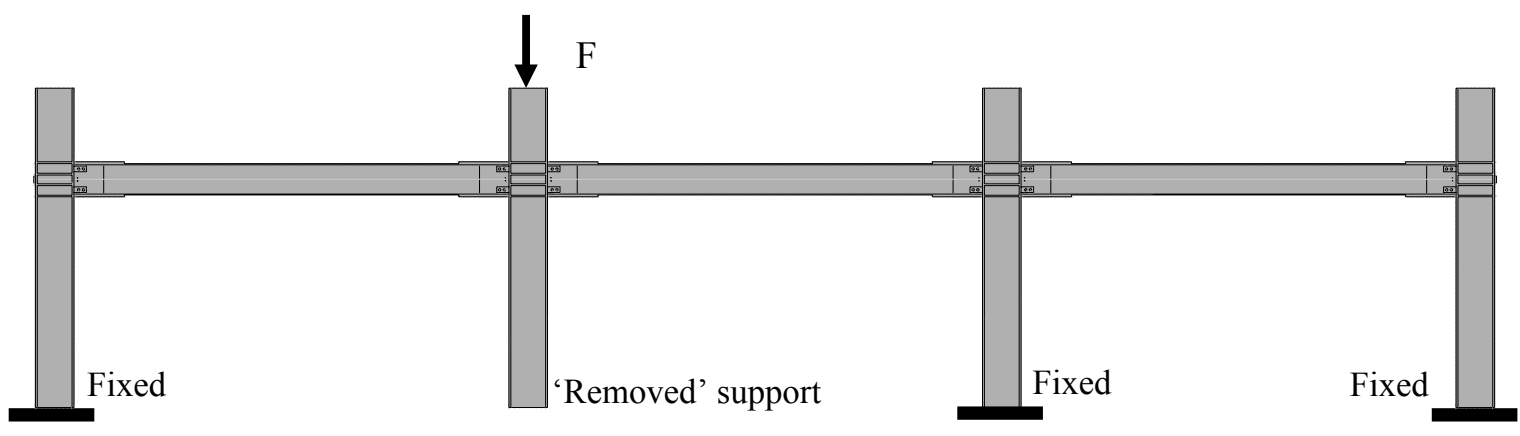

(a)

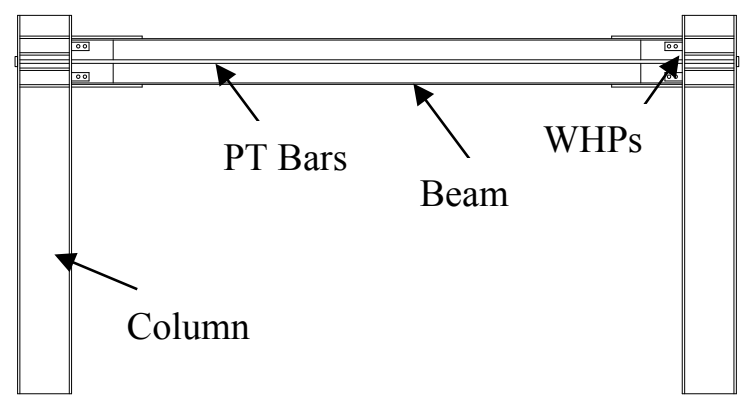

(b)

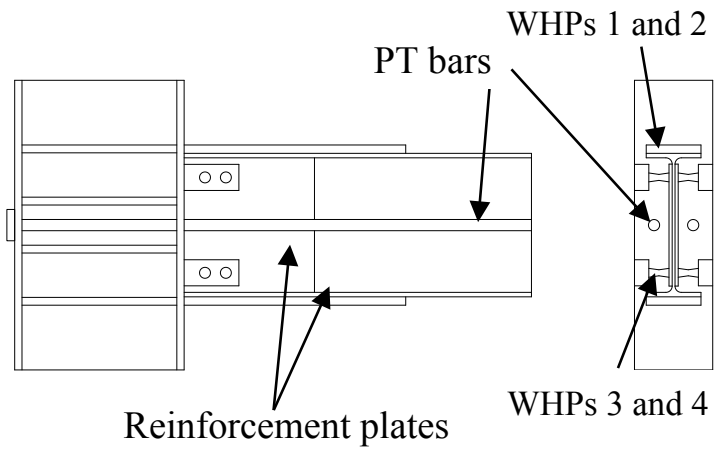

(c)

Fig. 2: (a) Elevation view of the SC-MRF; (b) frame with PT connections and WHPs; (c) detail of an exterior beam-column connection. 


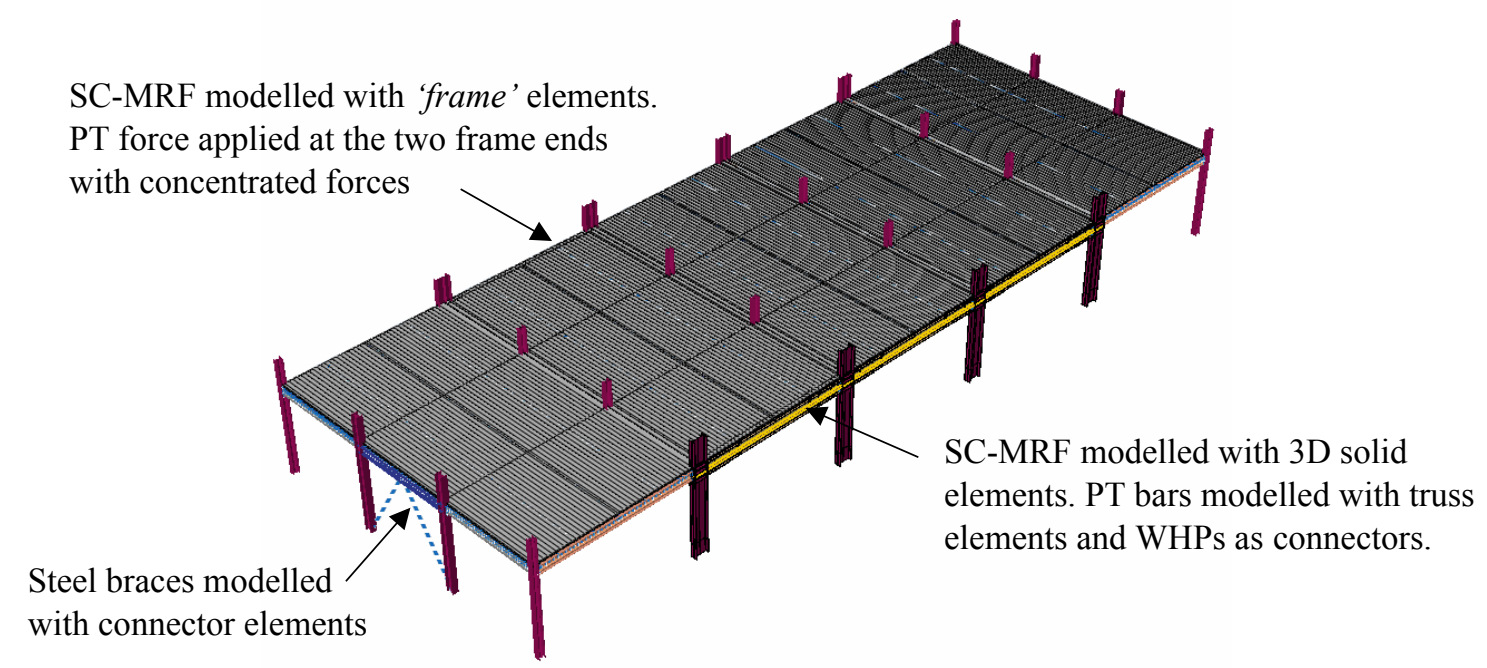

Fig. 3: Overview of the ABAQUS finite element model.

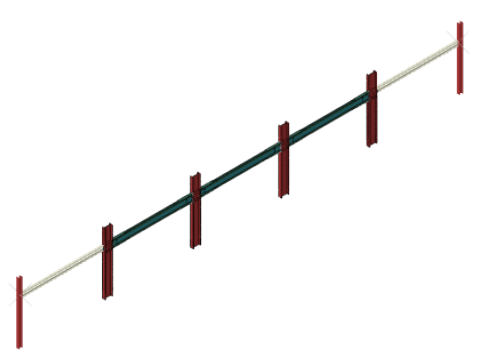

(a) Planar frame

(Model 1)

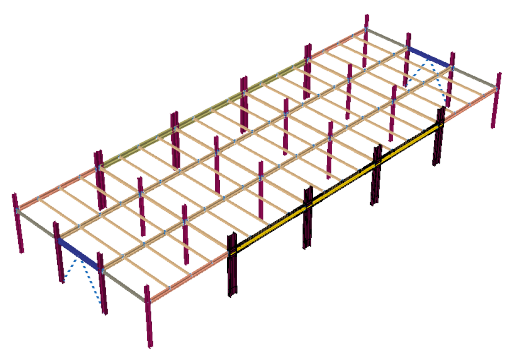

(b) 3D frame

(Model 2)

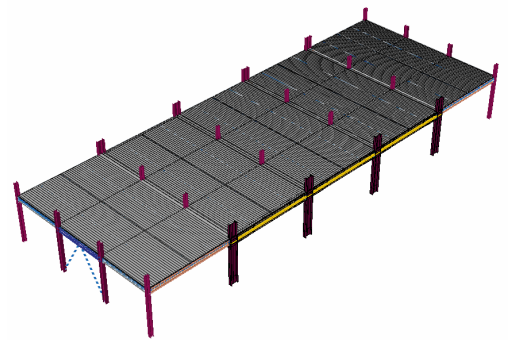

(c) 3D frame with slab

(Model 3)

Fig. 4: Versions of the ABAQUS finite element model.

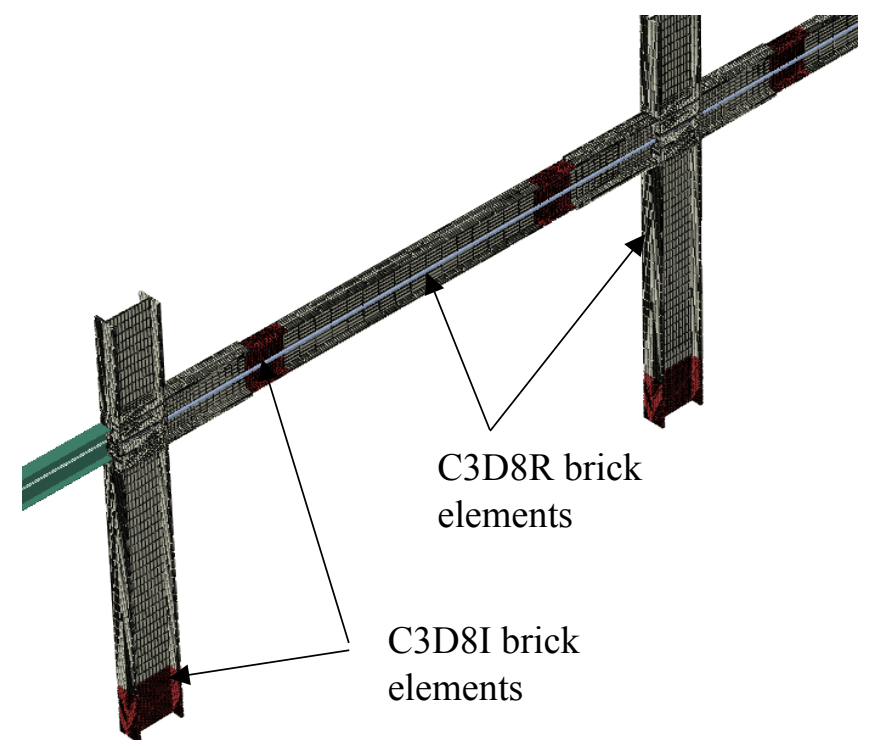

Fig. 5: SC-MRF of the frame A modelling. Different 8-node 3D solid elements. 


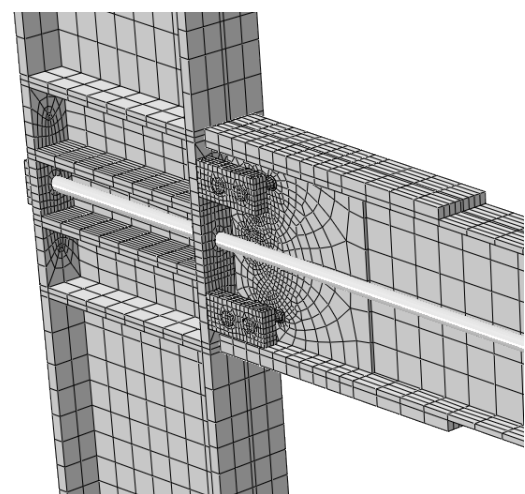

(a)

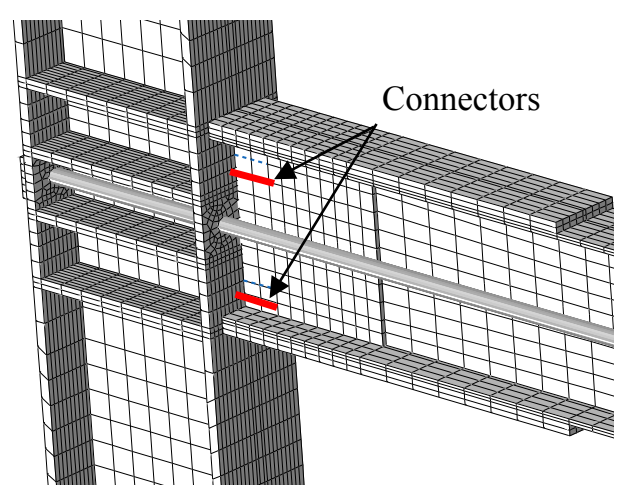

(b)

Fig. 6: ABAQUS model of the exterior beam-column connection. (a) with 3D WHPs; (b) with connector elements.

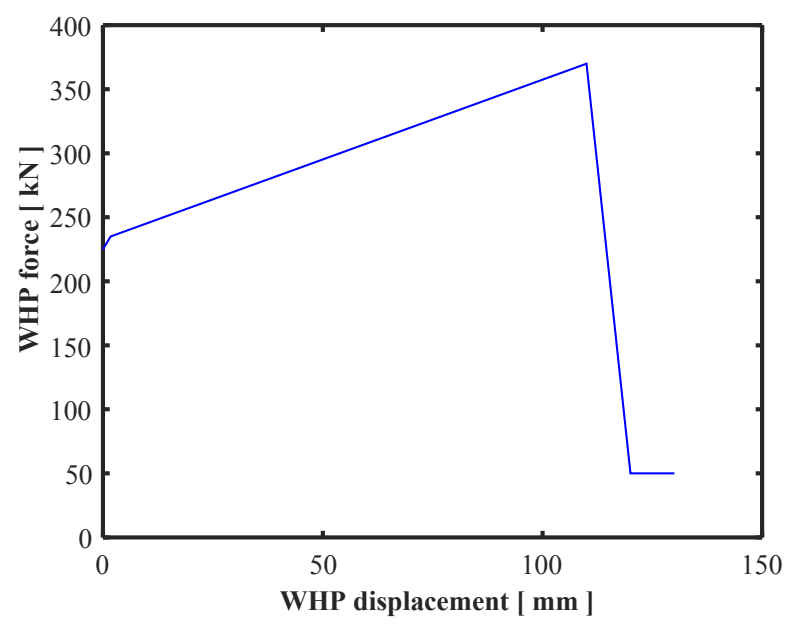

Fig. 7: WHPs. Force-displacement curve. 


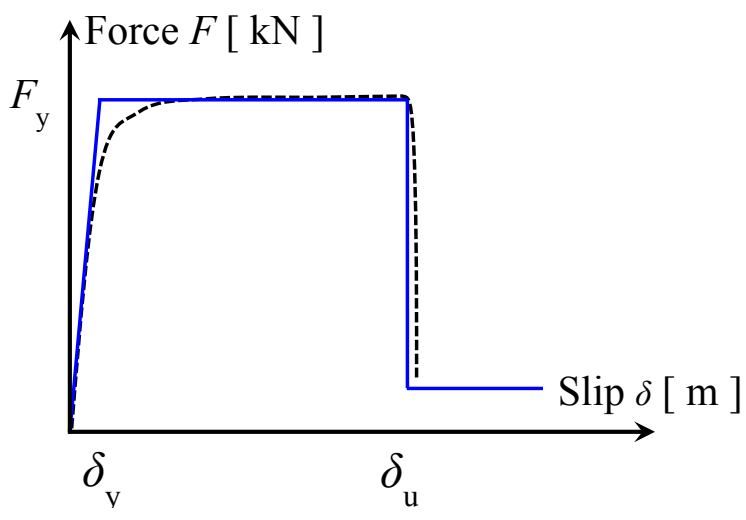

Fig. 8: Force-slip relationship of shear connectors. 


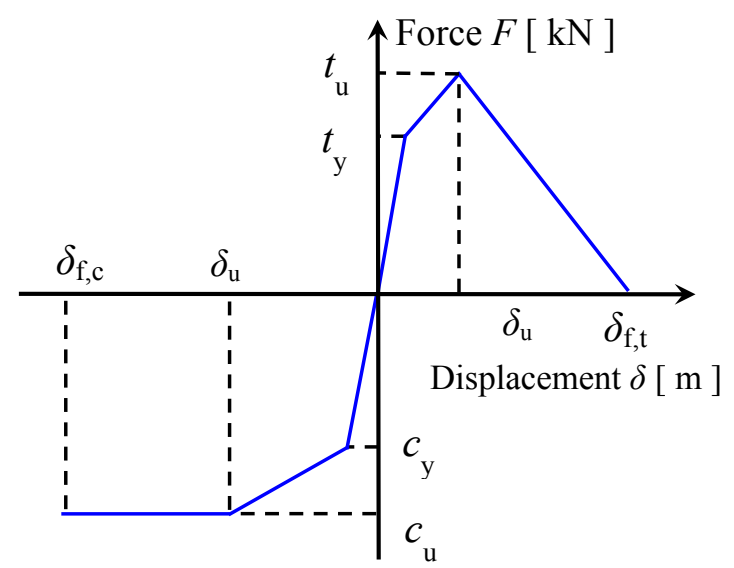

(a)

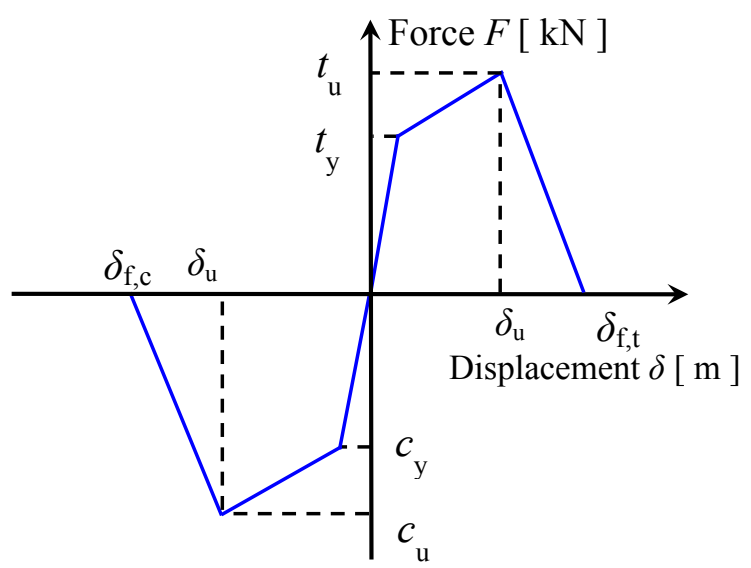

(b)

Fig. 9: Fin-plate connection. Constitutive laws for (a) ductile bearing failure at the holes; (b) brittle bolt shear failure.

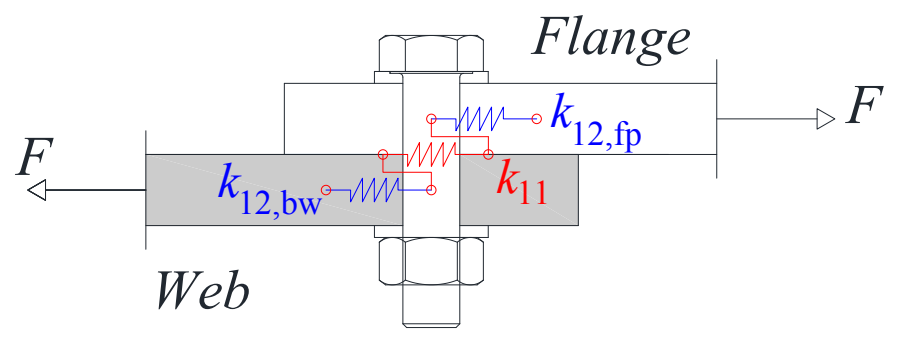

Fig. 10: Fin-plate connection. Idealization of the single bolt. 


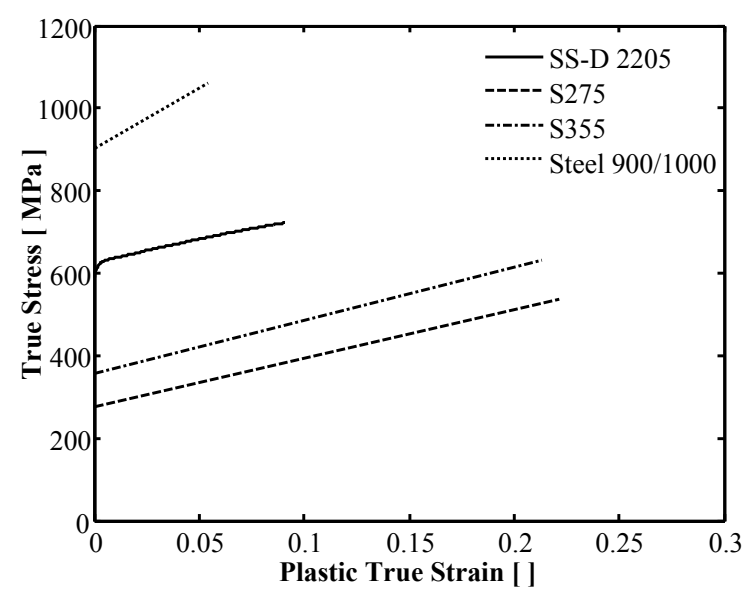

Fig. 11: Constitutive laws for the plastic true strain-stress for steel components.

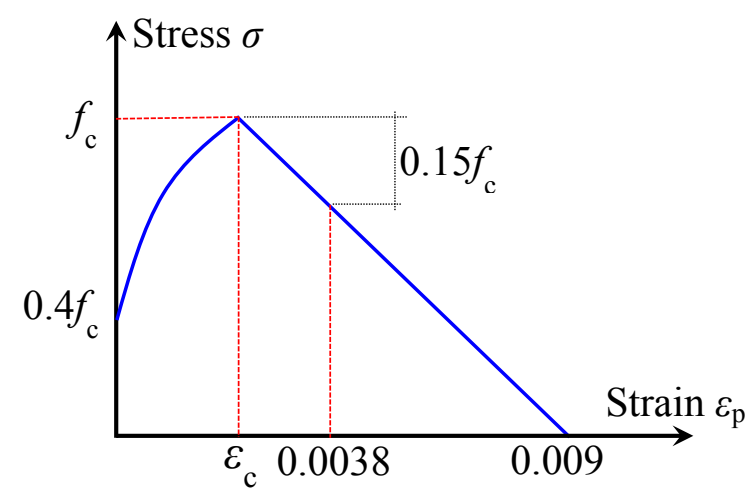

(a)

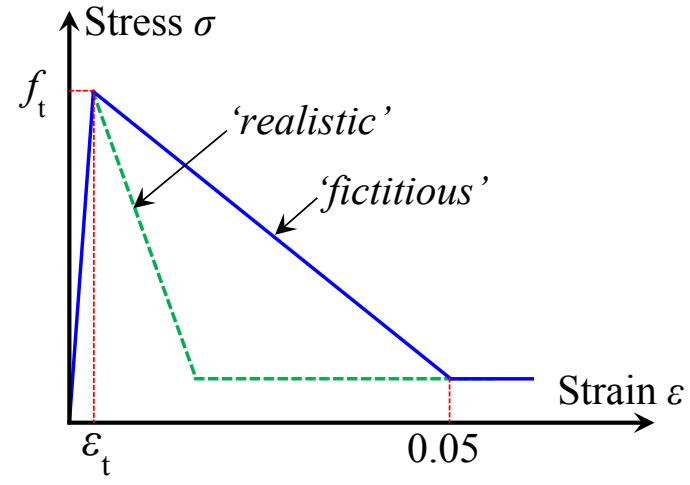

(b)

Fig. 12: Constitutive law for the (a) concrete plastic strain $\varepsilon_{\mathrm{p}}$-stress in compression; (b) the concrete stress-strain in tension ('realistic' and 'fictitious' softening). 


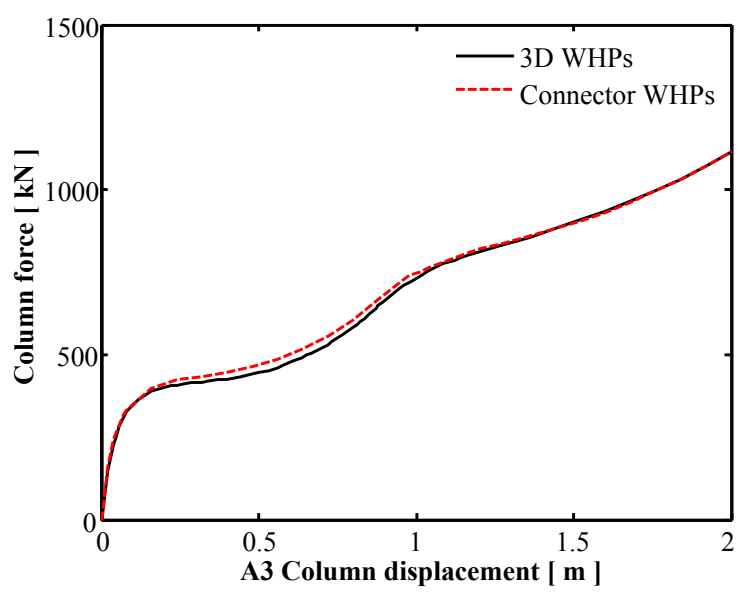

(a)

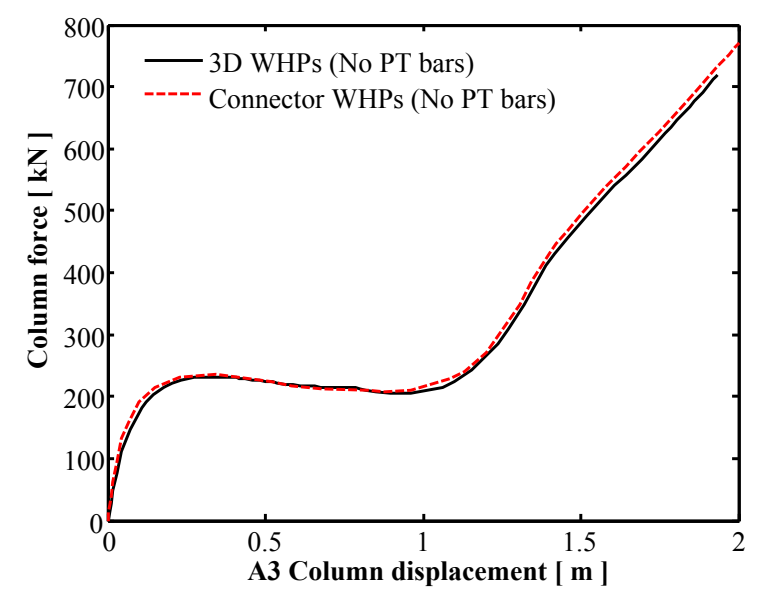

(b)

Fig. 13: WHPs models' comparison. Force-displacement curves for the detailed and simplified models. (a) With PT bars and (b) without PT bars. 


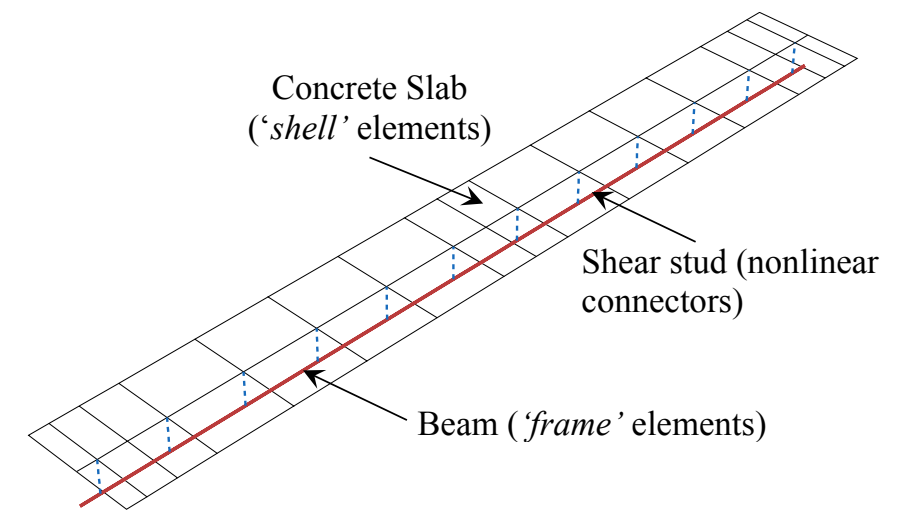

Fig. 14: Composite beam. Mechanical idealization.
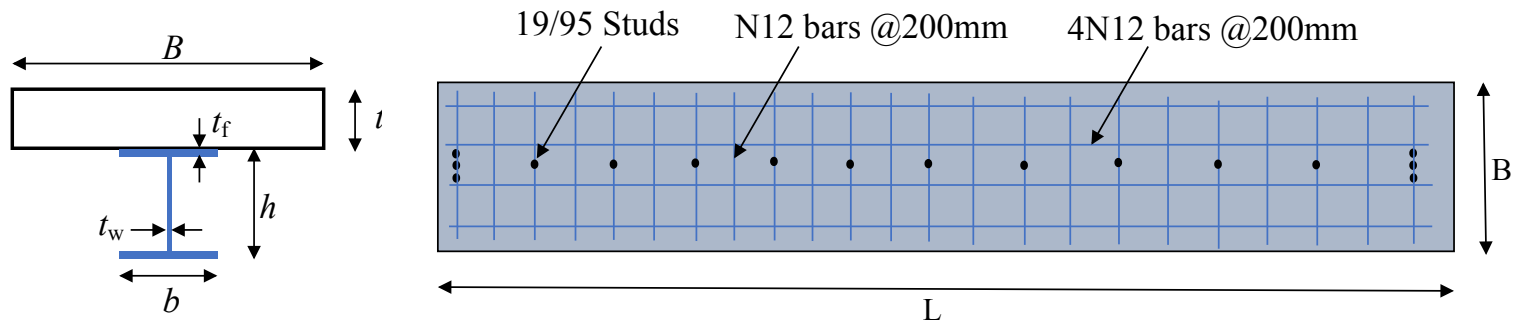

Fig. 15: Composite beams. Geometry including shear studs and rebars arrangement.

(According to [48] and [49]).

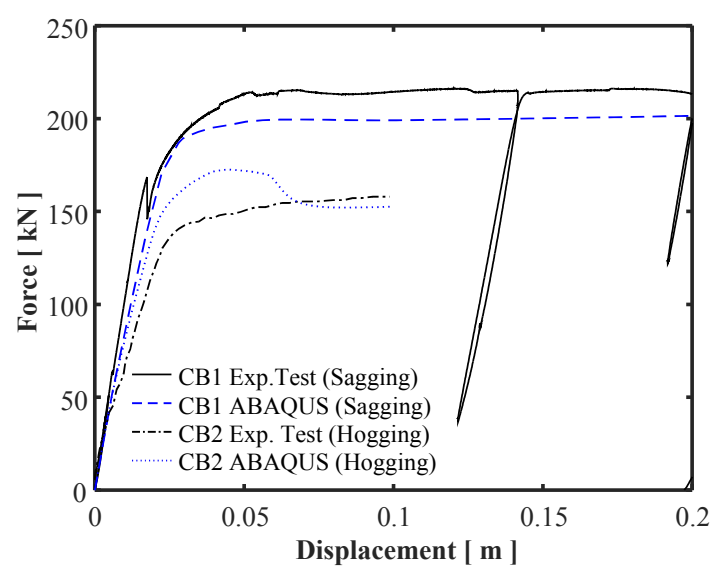

Fig. 16: Composite beams. Comparison of the force-displacement curves for numerical and experimental results under sagging and hogging bending moments. (According to [48] and [49]). 


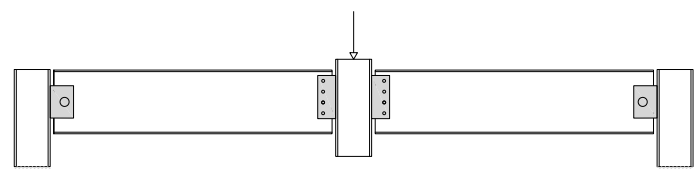

(a)

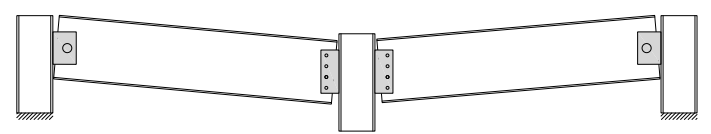

(b)

Fig. 17: Two-span beam assembly under pushdown loading with unsupported center column: (a) original configuration; (b) deformed configuration.

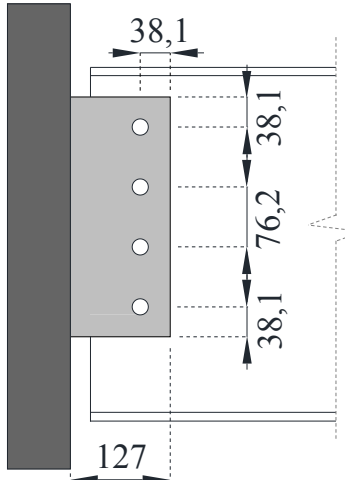

(a)

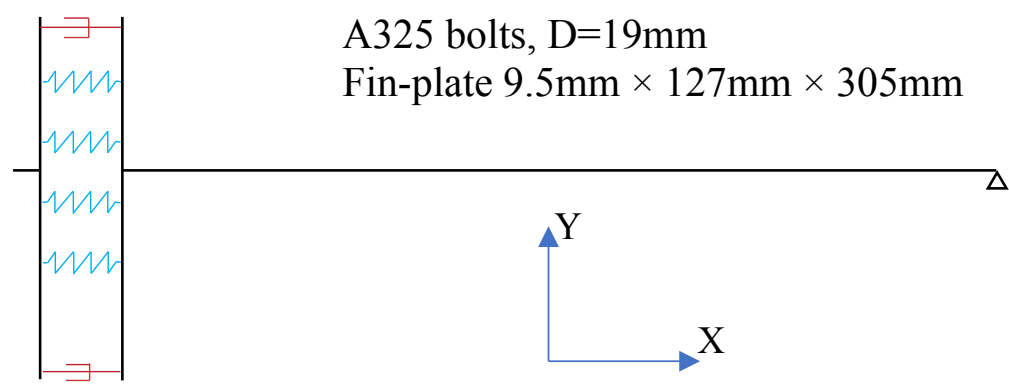

(b)

Fig. 18: (a) Fin-plate dimensions for the four-bolt case and (b) reduced model for the two-span beam assembly of Thompson [56].

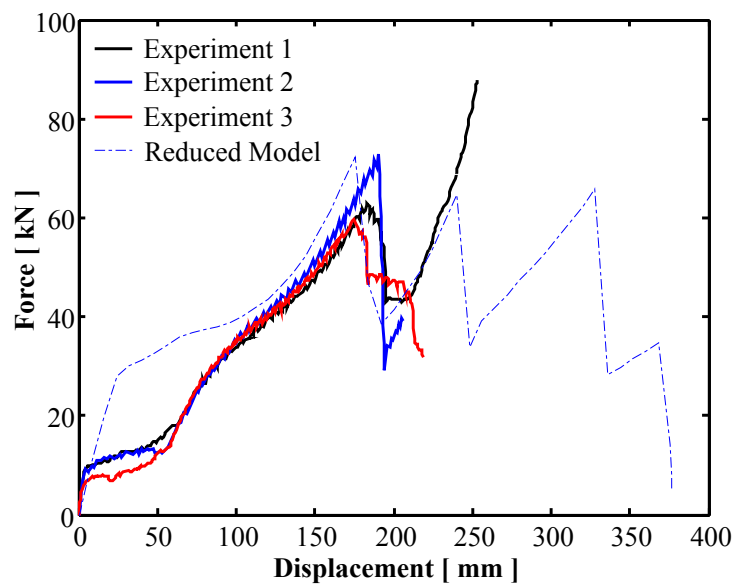

Fig. 19: Fin-plates. Force-displacement curves from experiments and reduced model. 


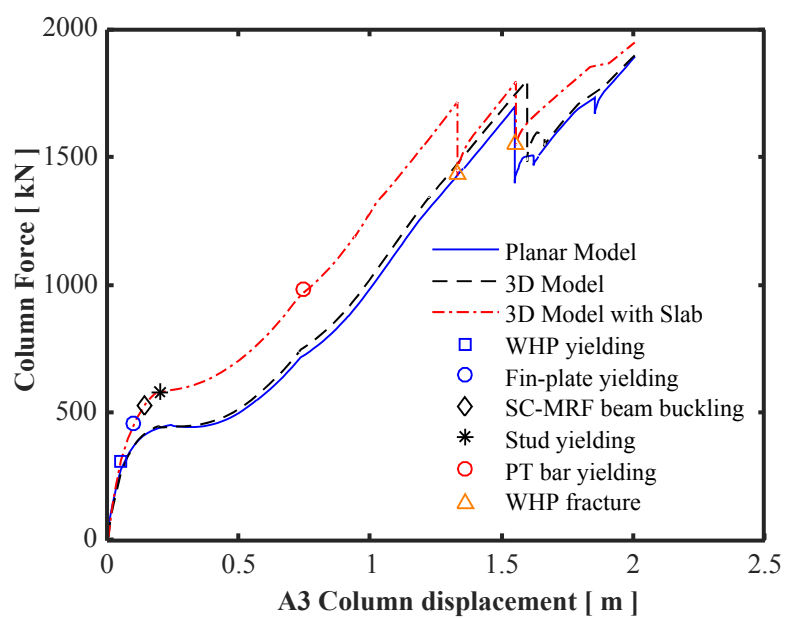

Fig. 20: 'Push-down' analyses. Force-displacement curves for Models 1, 2 and 3. 


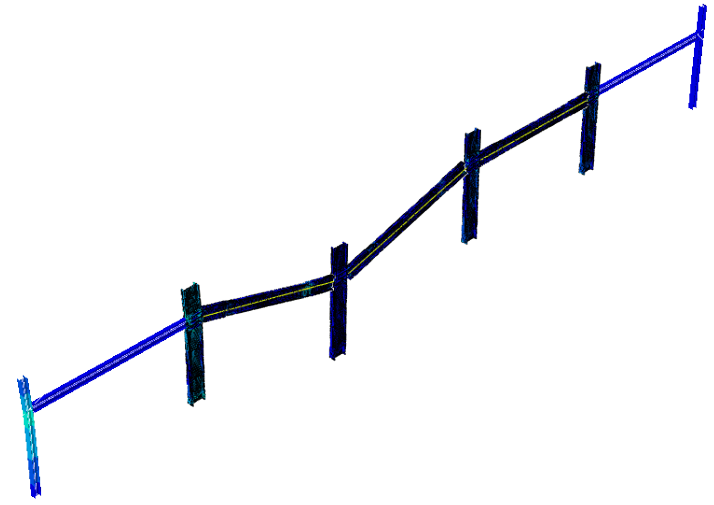

(a)

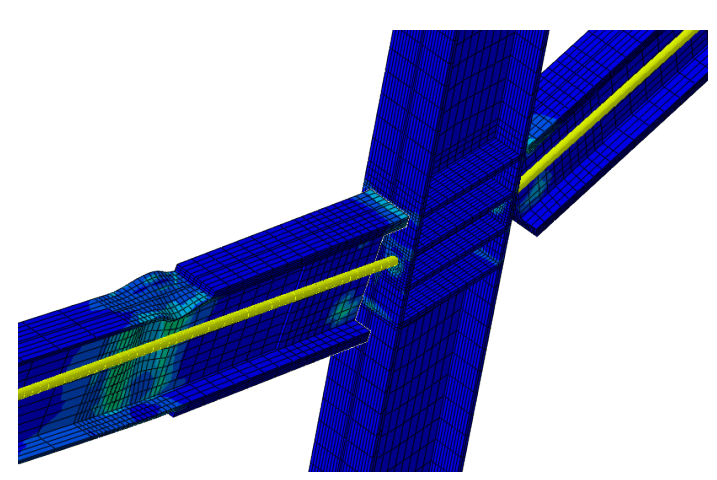

(b)

Fig. 21: Planar frame (Model 1). A3 column loss scenario. (a) Deformed configuration; (b) local buckling at the SC-MRF beam.

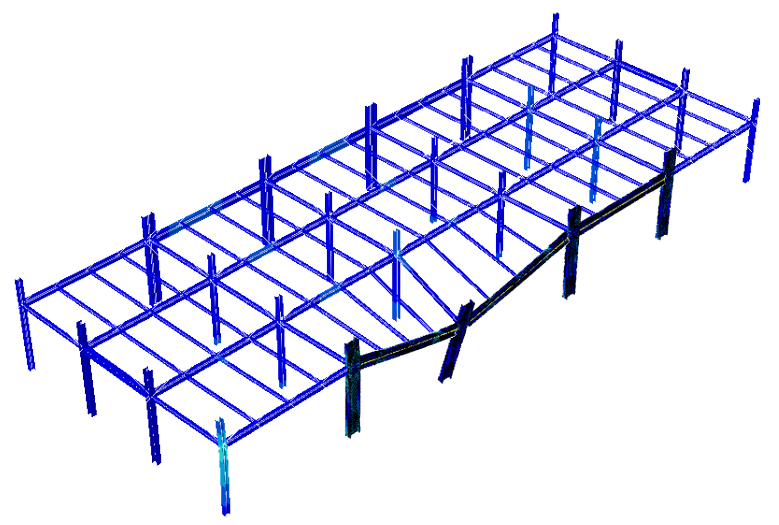

(a)

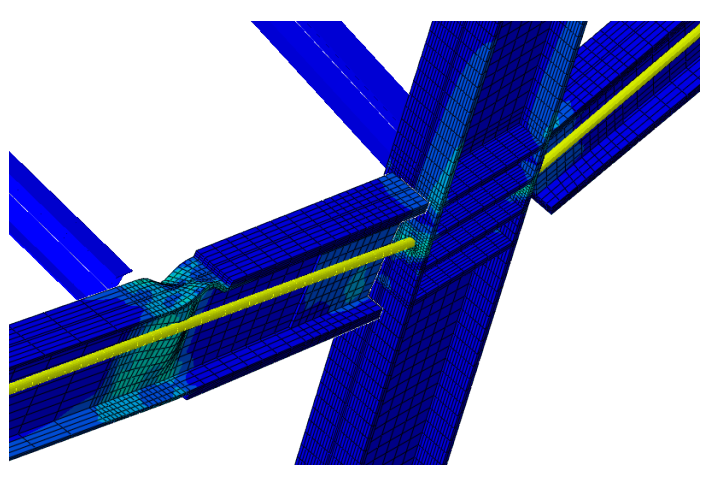

(b)

Fig. 22: 3D frame (Model 2). A3 column loss scenario. (a) Deformed configuration; (b) local buckling at the SC-MRF beam.

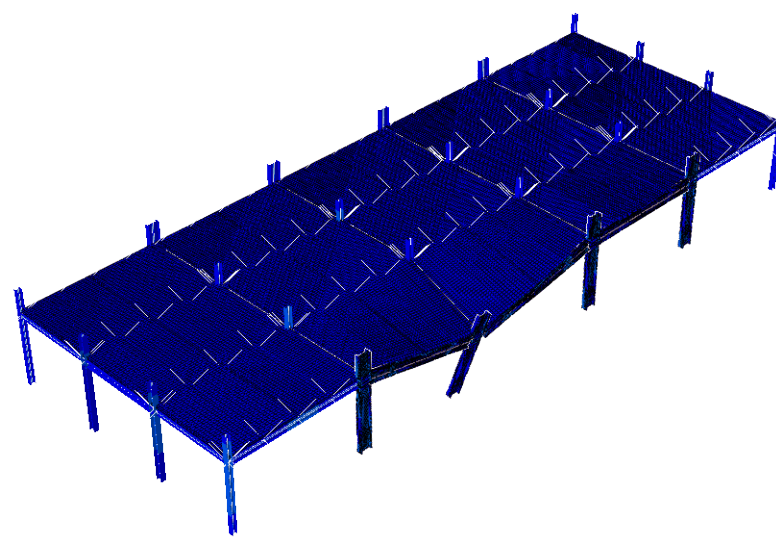

(a)

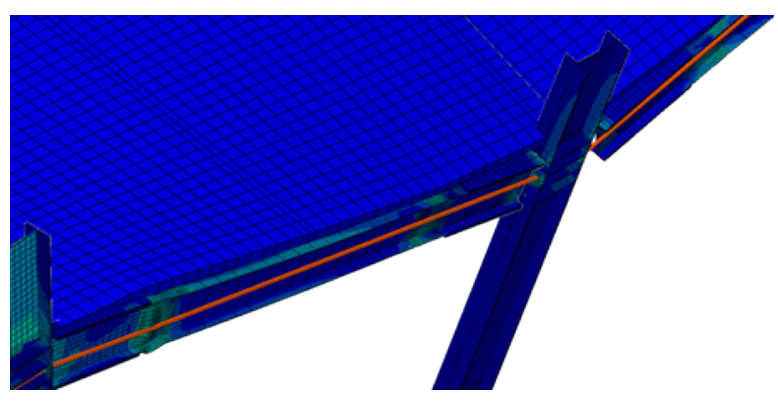

(b)

Fig. 23: 3D frame with slab (Model 3). A3 column loss scenario. (a) Deformed configuration; (b) local buckling at the SC-MRF beam. 


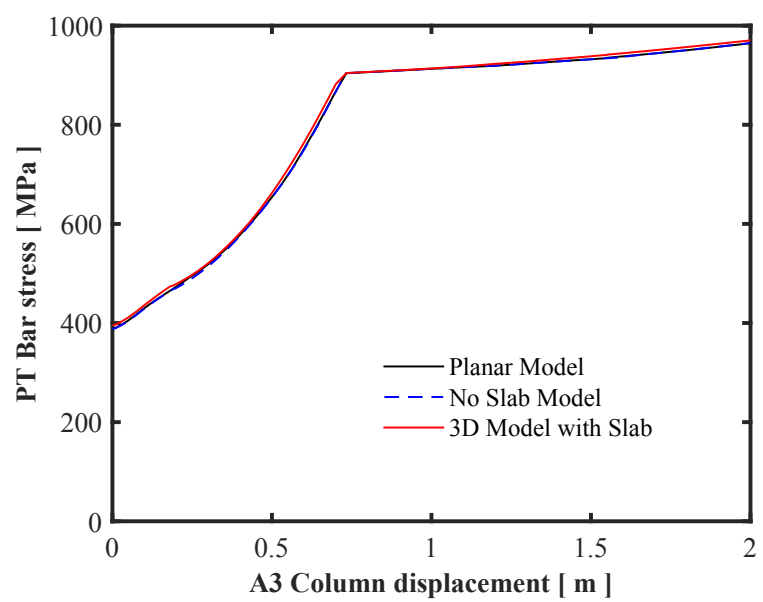

Fig. 24: Force-displacement curves for PT bars of Models 1, 2 and 3.

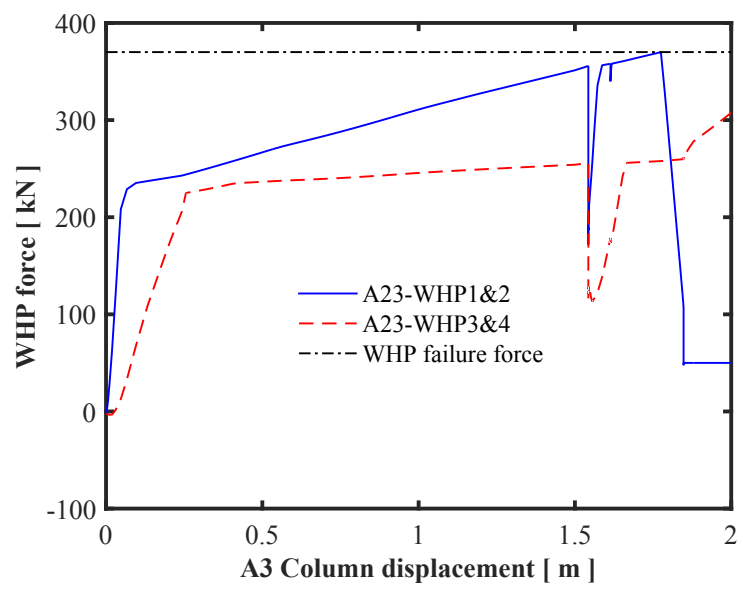

(a)

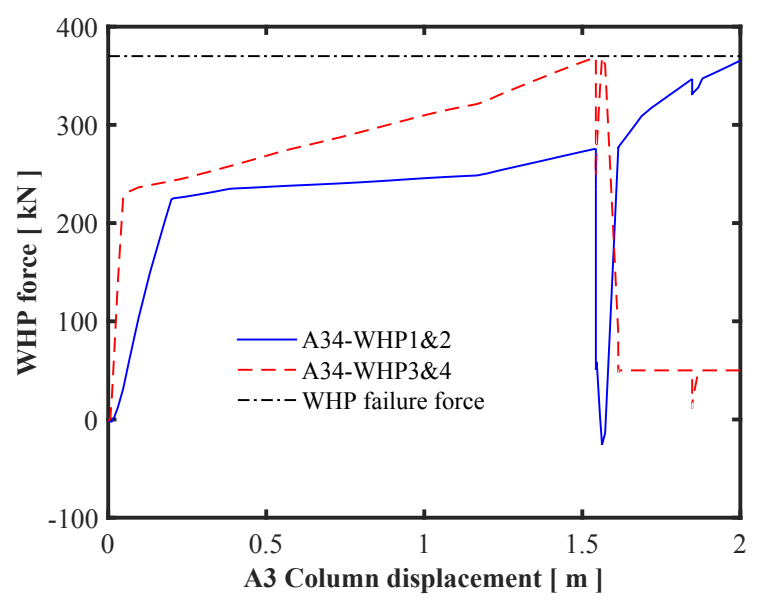

(c)

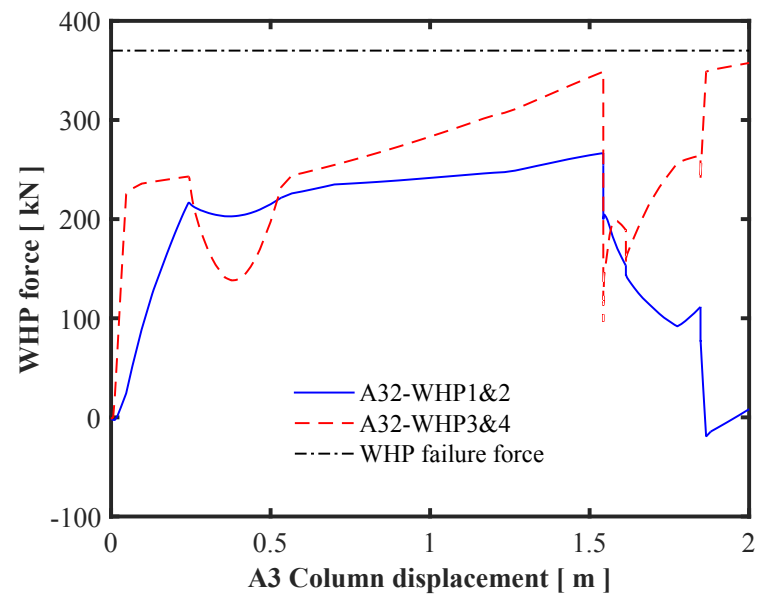

(b)

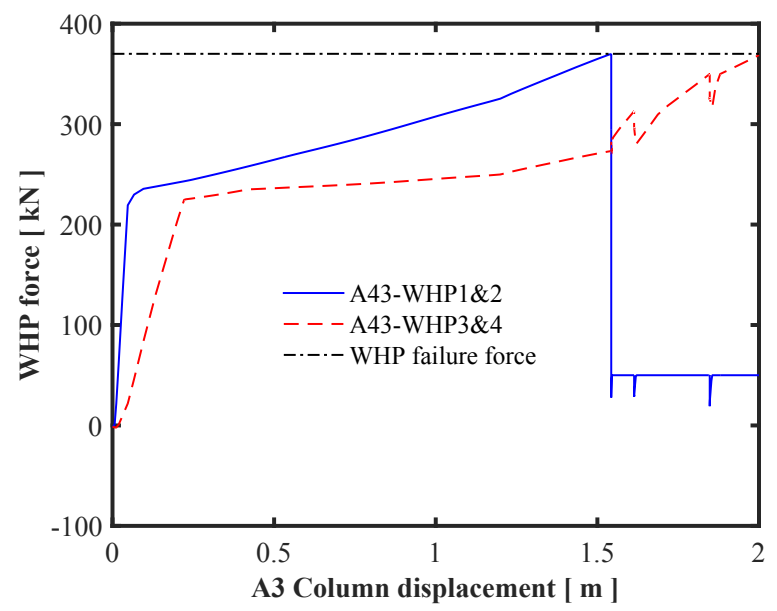

(d)

Fig. 25: Evolution of WHP force for (1) Planar frame (Model 1) and (2) 3D model (Model 2). 


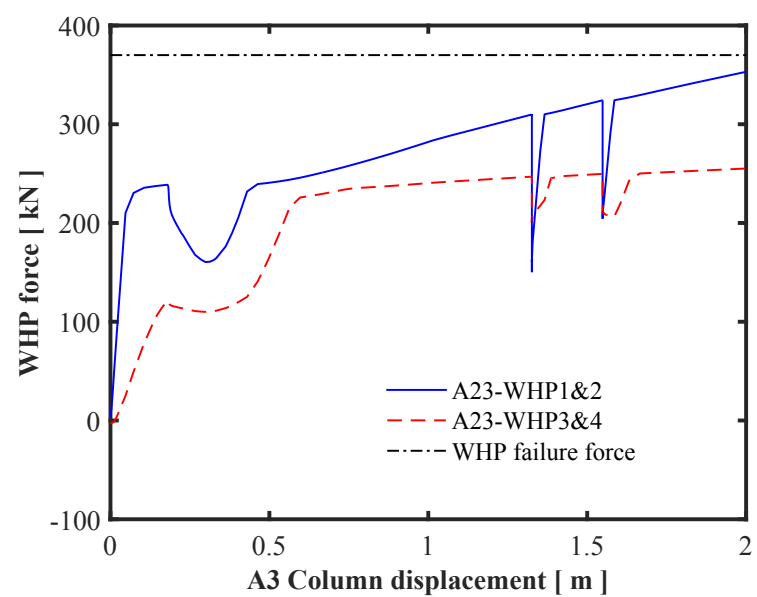

(a)

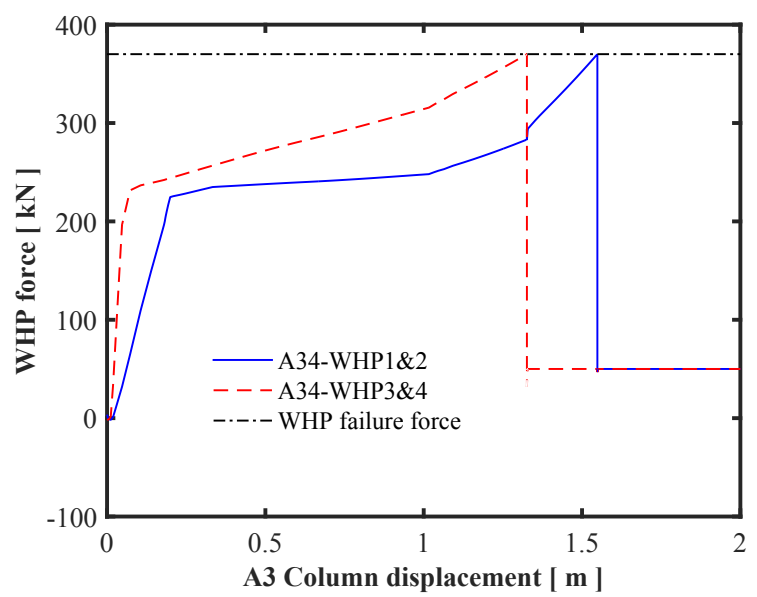

(c)

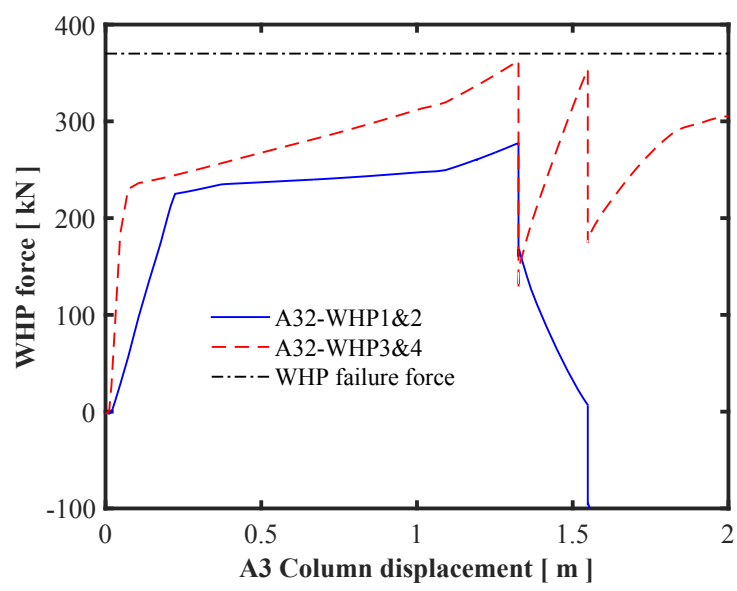

(b)

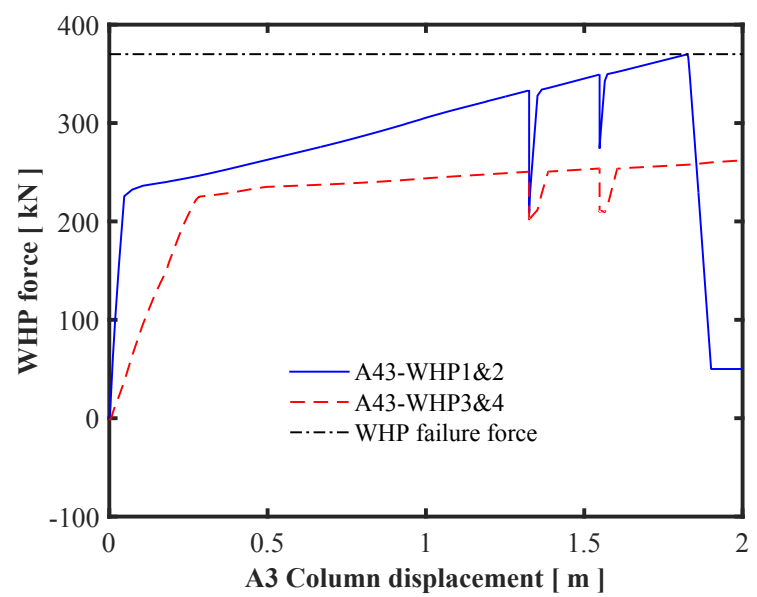

(d)

Fig. 26: Evolution of WHP force for 3D model with slab (Model 3). 


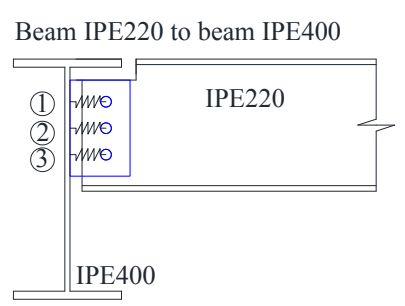

(a)

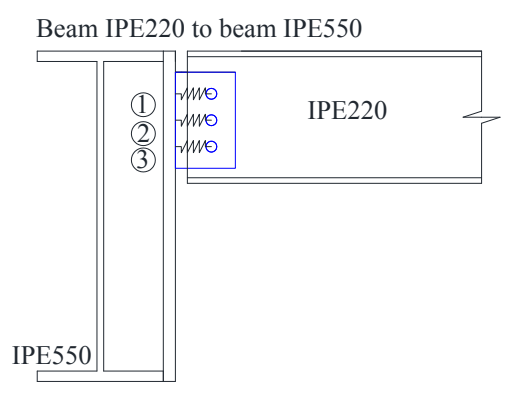

(b)

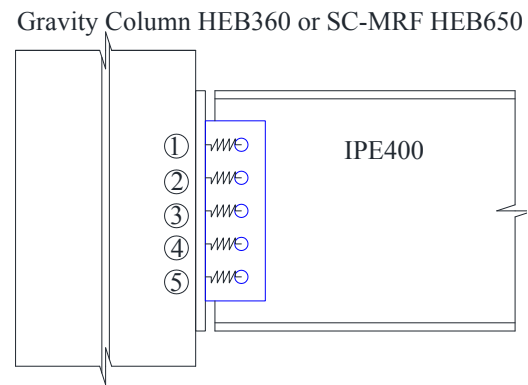

(c)

Fig. 27: Fin-plate connections. (a) Secondary beam to main beam of the gravity frame; (b) secondary beam to beam of the SC-MRF; (c) main beam of the gravity frame to the columns. 


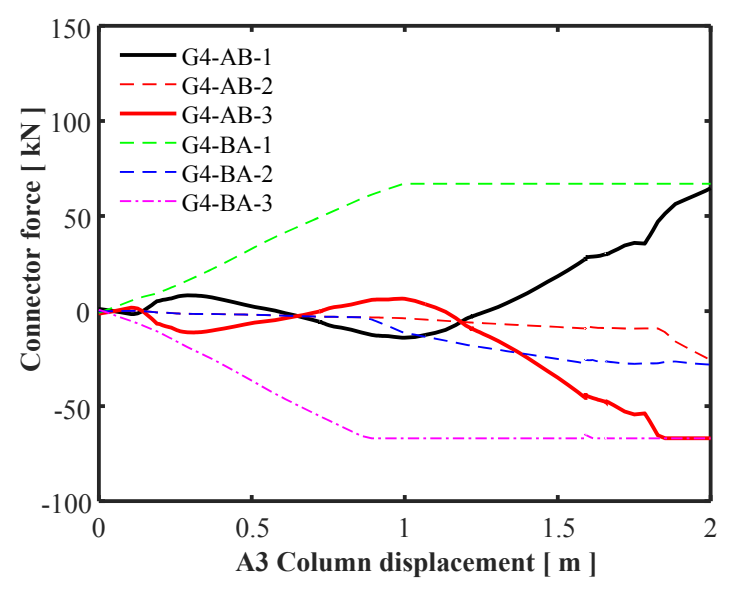

(a)

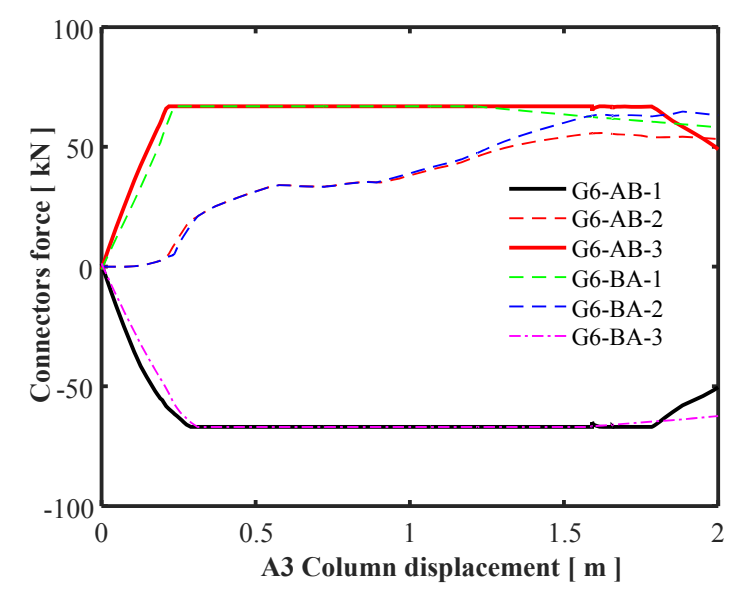

(c)

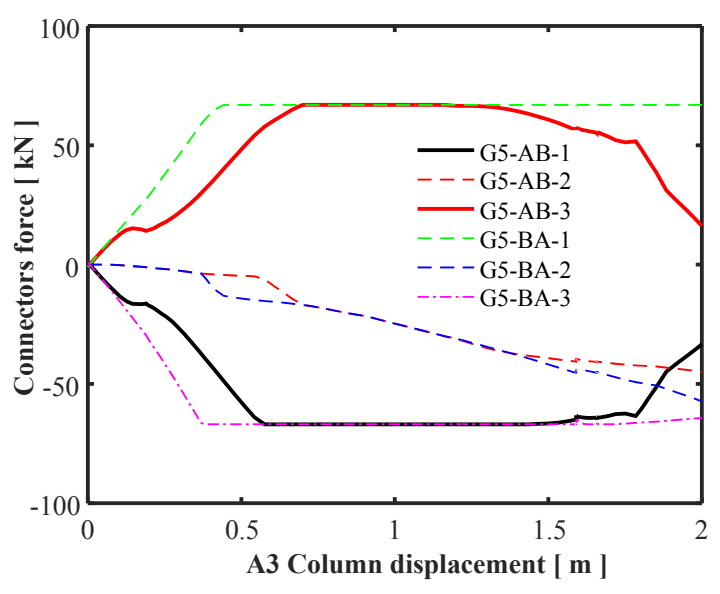

(b)

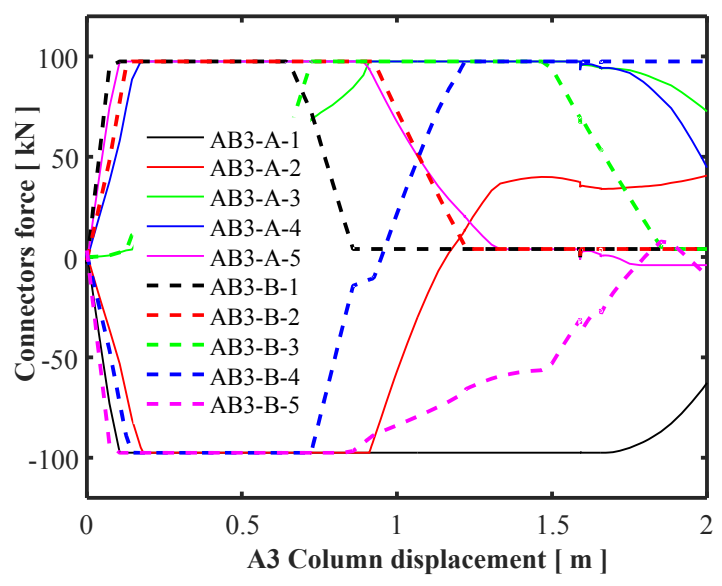

(d)

Fig. 28: 3D frame (Model 2). Shear force on the bolts of the fin-plate connections of the: (a) G4 beam; (b) G5 beam; (c) G6 beam; (d) AB3 beam. 


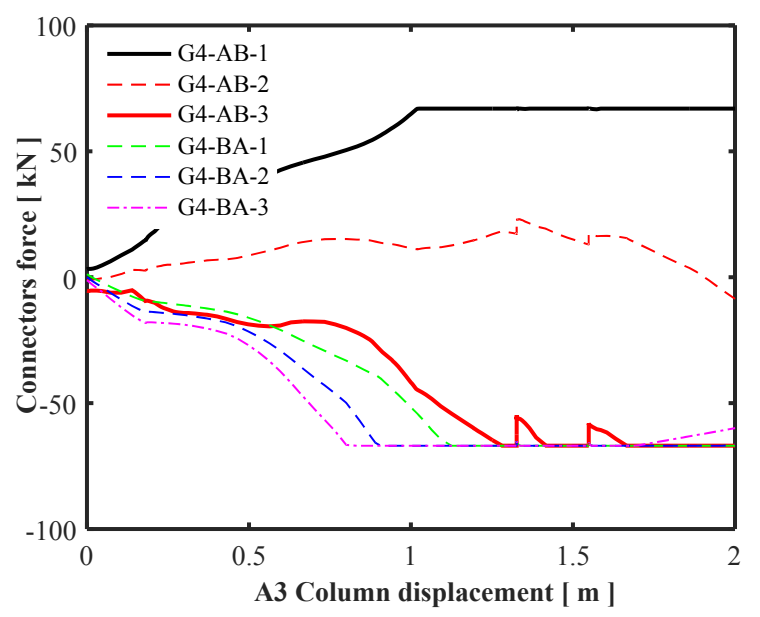

(a)

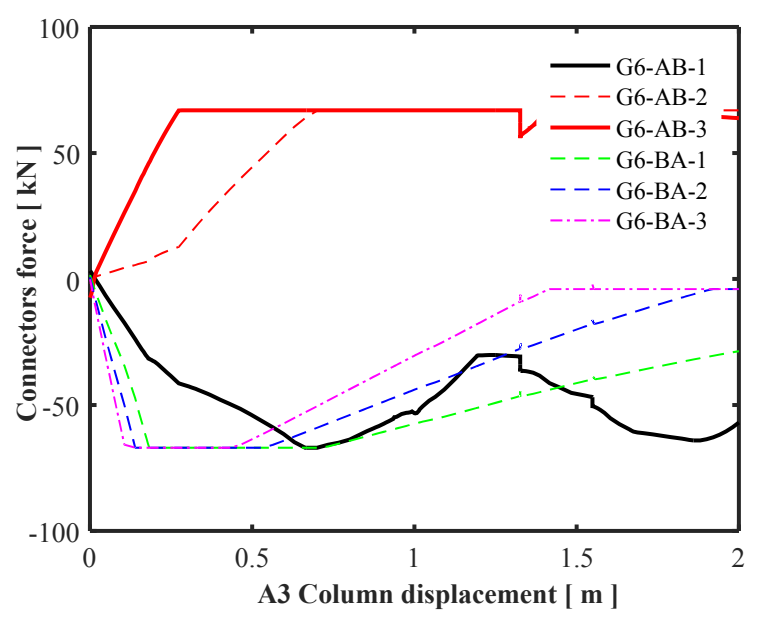

(c)

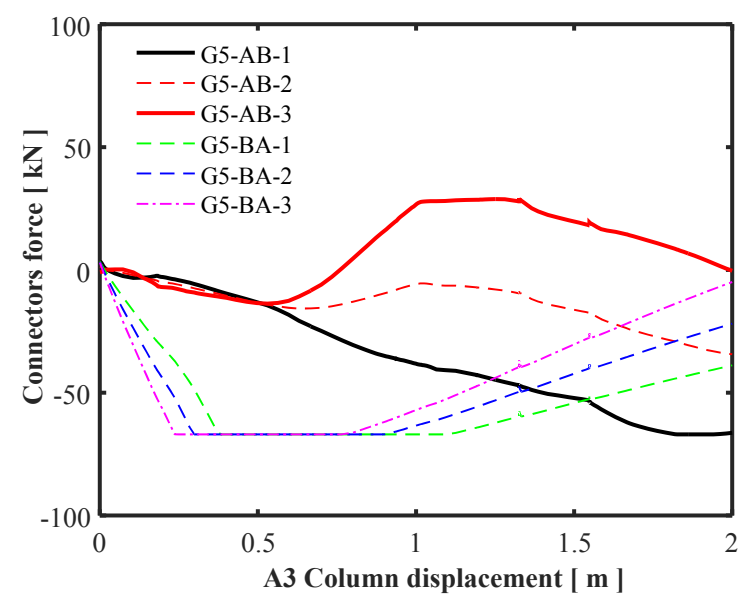

(b)

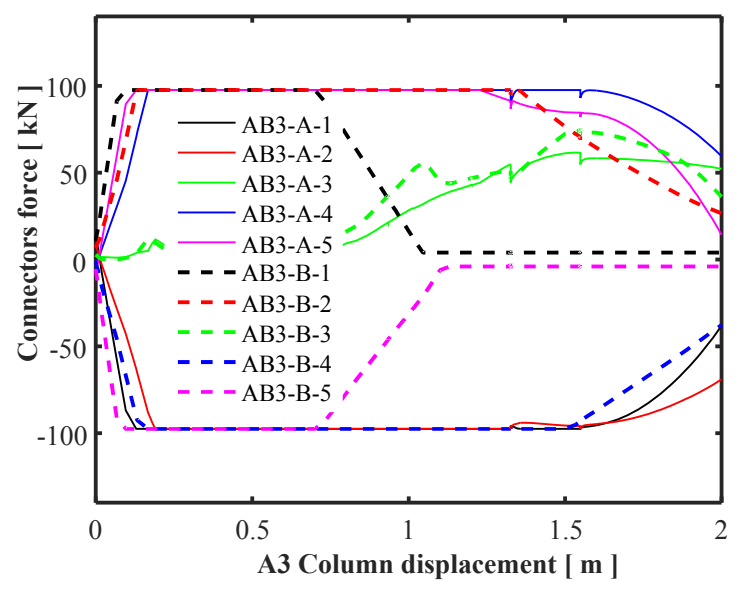

(d)

Fig. 29: 3D frame with slab (Model 3). Shear force on the bolts of the fin-plate connections of the: (a) G4 beam; (b) G5 beam; (c) G6 beam; (d) AB3 beam. 


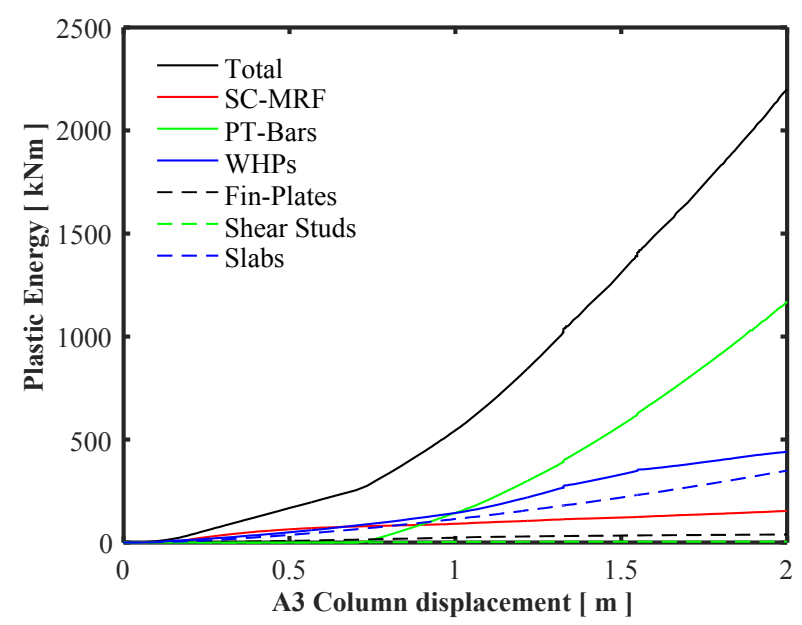

Fig. 30: 3D frame with slab (Model 3). Variation of the plastic energy with the displacement of column A3 for all components of the structure.

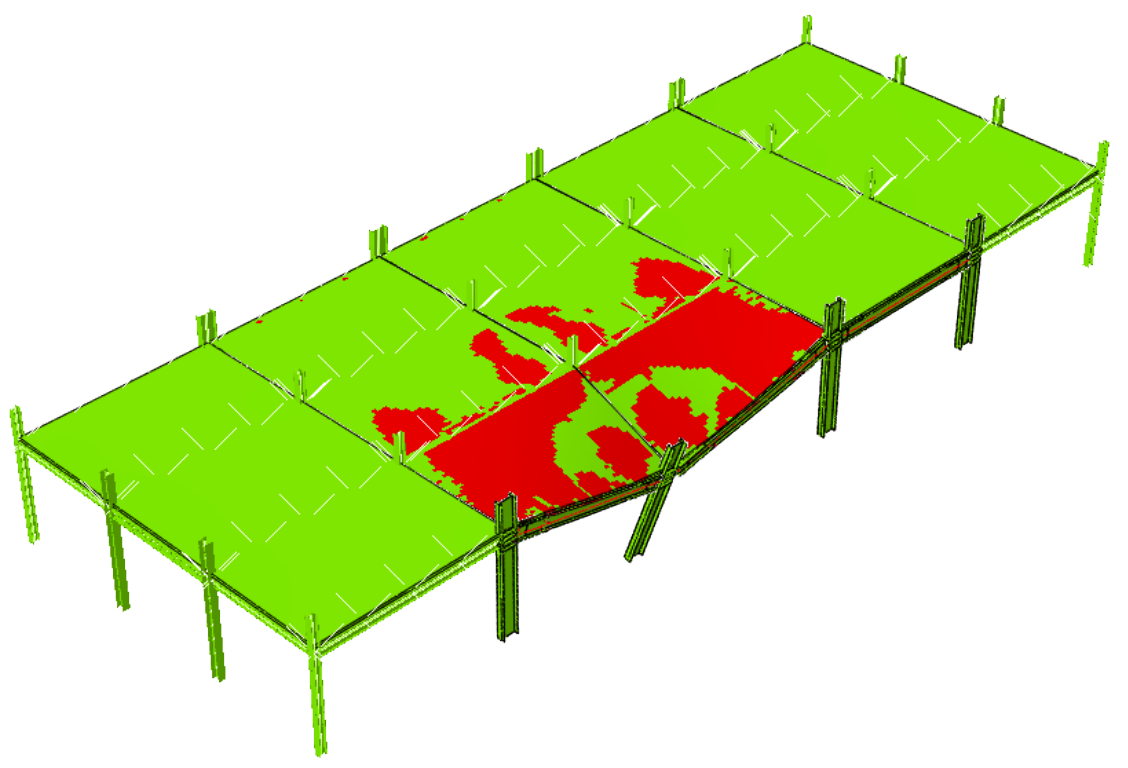

Fig. 31: 3D frame with slab (Model 3). Plastic deformations in the slabs corresponding to a vertical displacement of column A3 of $2 \mathrm{~m}$. 


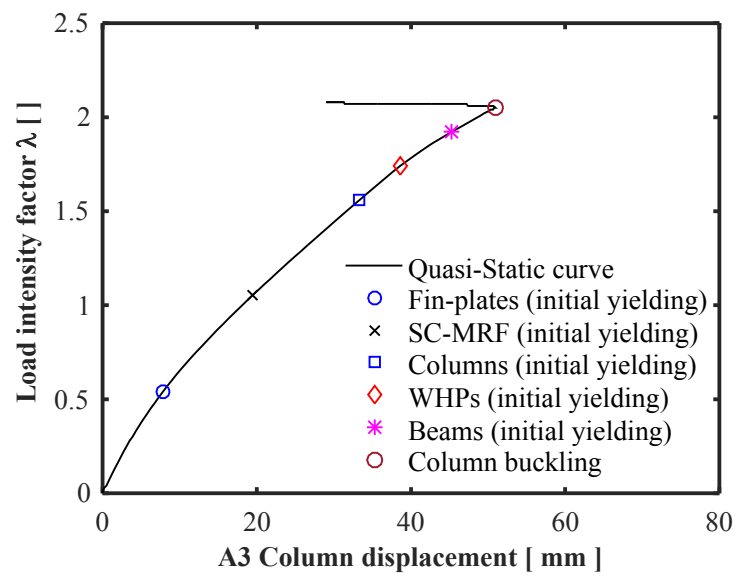

(a)

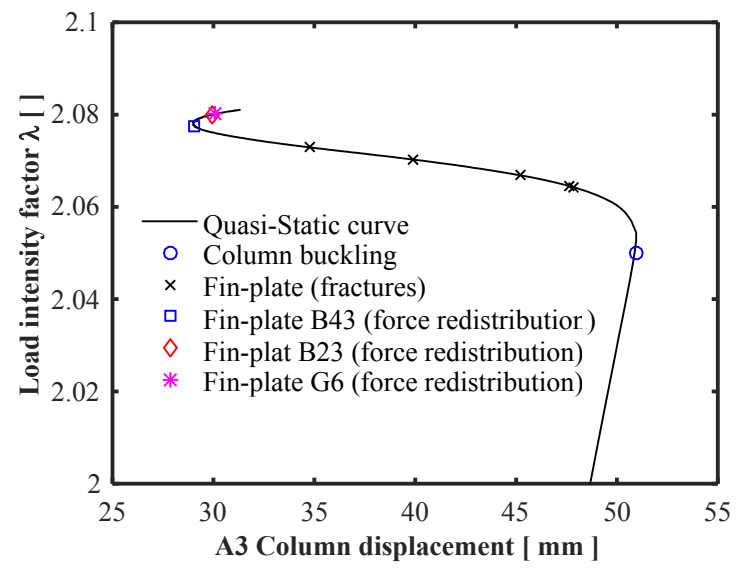

(b)

Fig. 32: 3D frame with slab (Model 3). $\lambda-U$ curve for the quasi-static analysis. (a) Overall behavior; (b) detail of the post-buckling behavior.

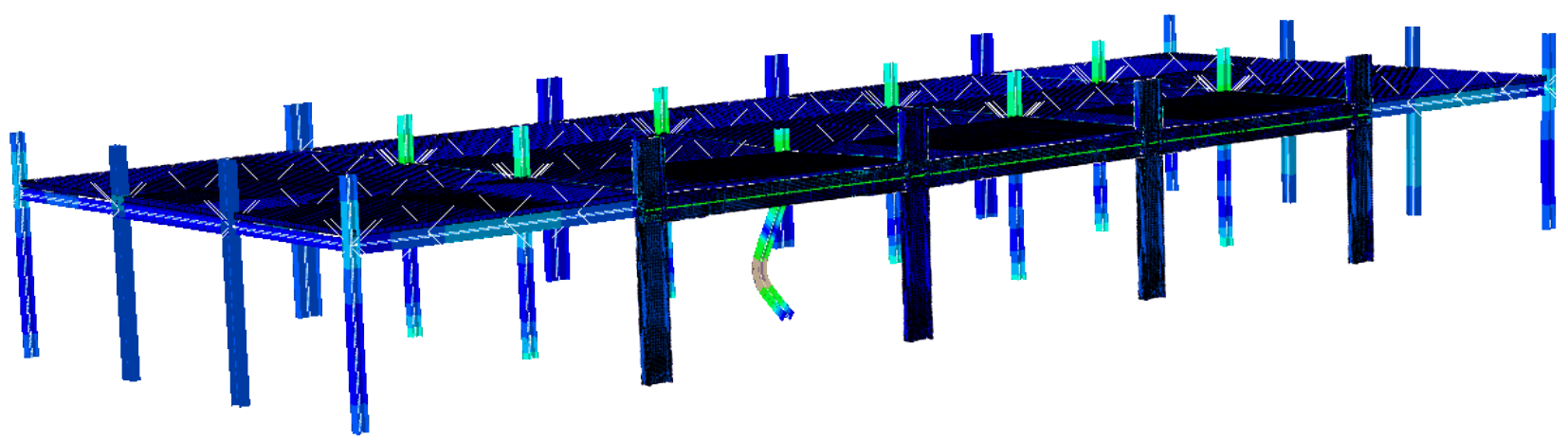

Fig. 33: 3D frame with slab (Model 3). Column B3 buckling for $\lambda$ equal to 2.05 corresponding to a vertical displacement of column A3 of $50 \mathrm{~mm}$. 


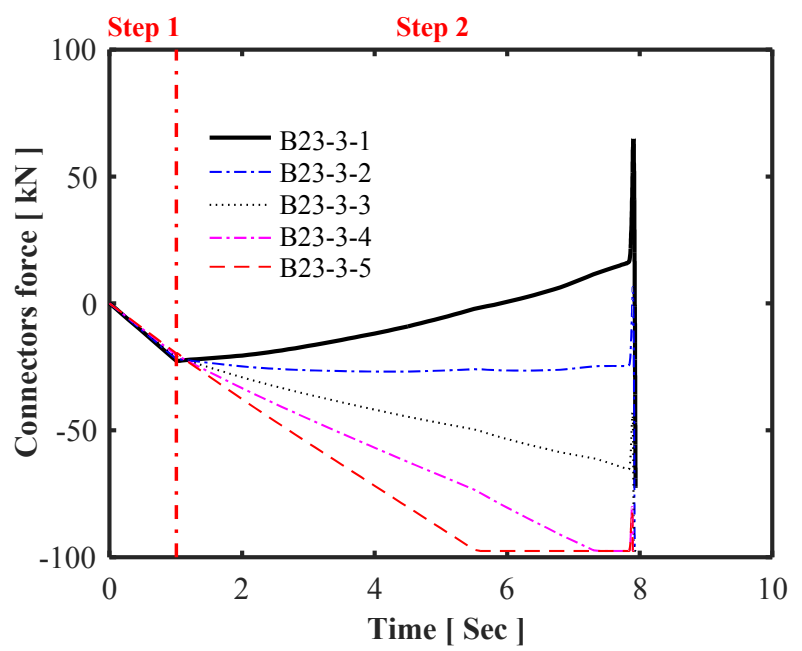

Fig. 34: 3D frame with slab (Model 3). Shear force on the bolts of the fin-plate connections for B23-3. 


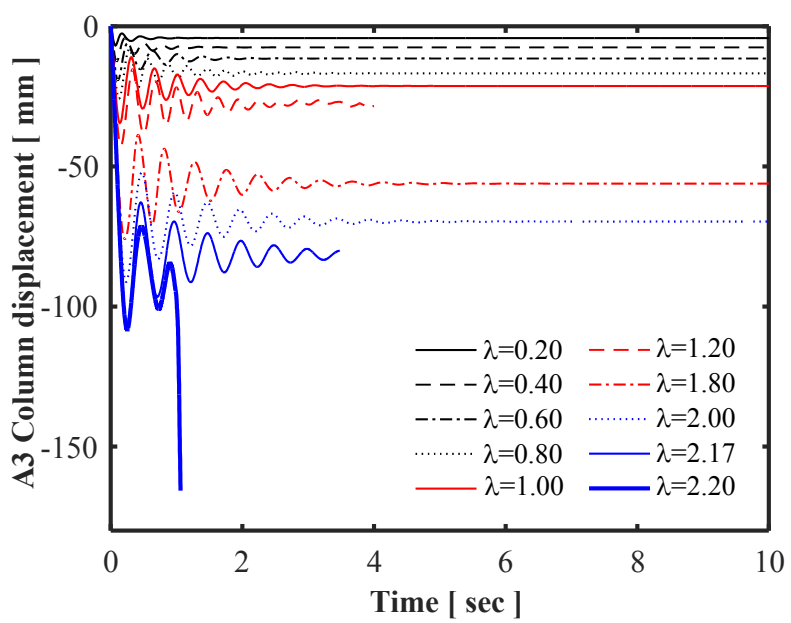

Fig. 35: 3D frame with slab (Model 3). Time history of the displacement of the 'removed' A3 column.

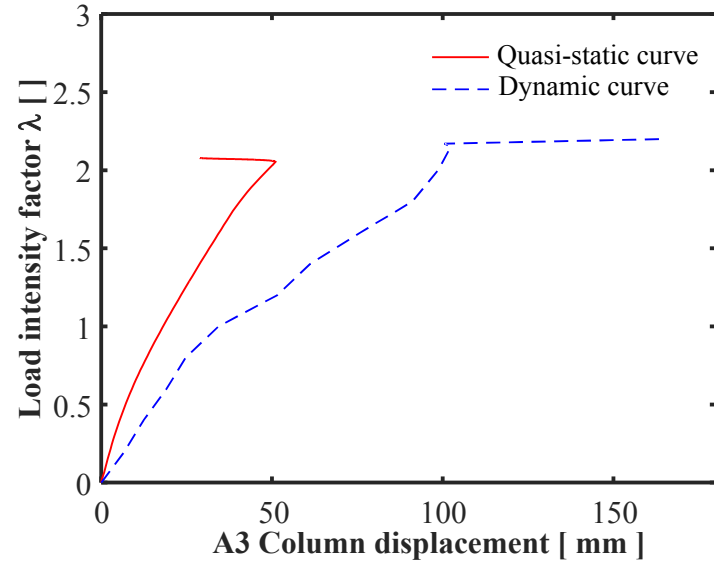

(a)

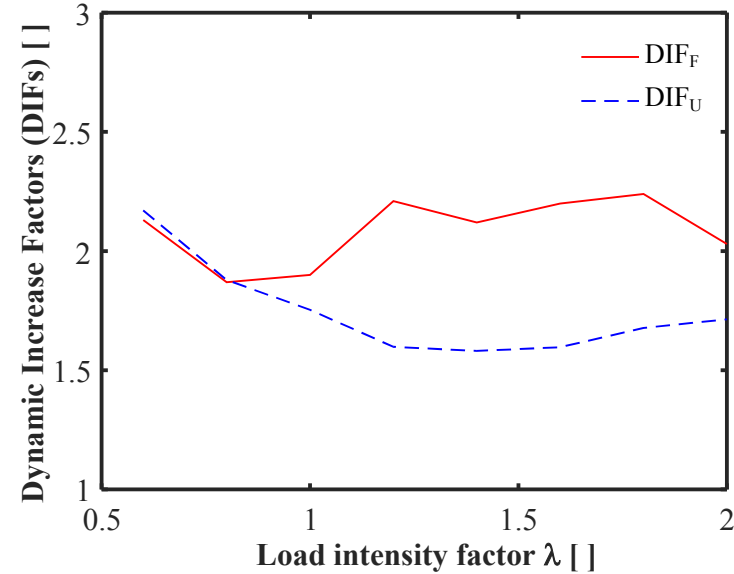

(b)

Fig. 36: 3D frame with slab (Model 3). (a) $\lambda$-U curve for the quasi-static and dynamic analyses; (b) Dynamic Increase Factor based on displacement (DIF ${ }_{U}$ ) or load intensity factor $\left(\mathrm{DIF}_{\mathrm{F}}\right)$. 


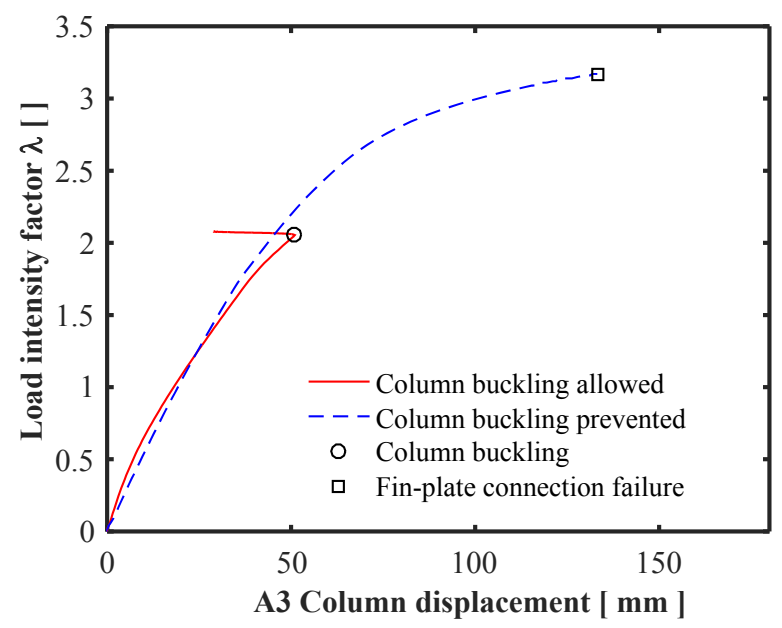

Fig. 37: 3D frame with slab (Model 3). $\lambda$-U curves. Effect of columns' buckling. 


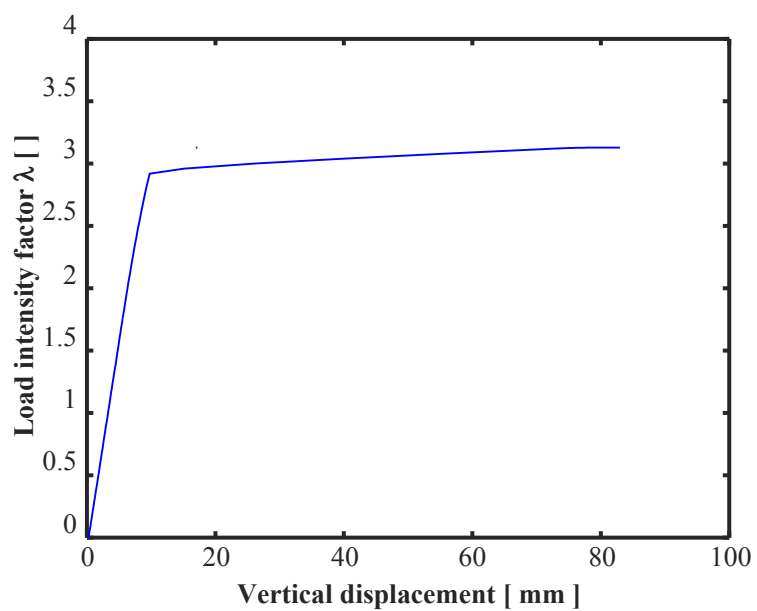

(a)

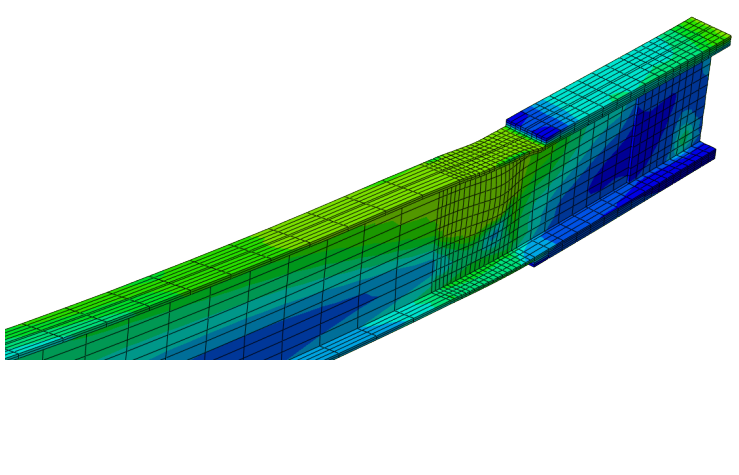

(b)

Fig. 38: 3D frame with slab (Model 3) with columns' buckling prevented. Failure modes. (a) Failure of the fin-plates due to shear forces (beam B32); (b) local buckling in the beam of the SC-MRF next to the 'removed' column (magnified by 10 times). 
Table 1: Material Properties.

\begin{tabular}{cccccccc}
\hline Elements & Steel Grade & $\begin{array}{c}E \\
{[\mathrm{GPa}]}\end{array}$ & $\begin{array}{c}f_{y} \\
{[\mathrm{MPa}]}\end{array}$ & $\begin{array}{c}f_{u} \\
{[\mathrm{MPa}]}\end{array}$ & $\begin{array}{c}\beta \\
{[-]}\end{array}$ & $\begin{array}{c}v \\
{[-]}\end{array}$ & $\begin{array}{c}\varepsilon_{u} \\
{[-]}\end{array}$ \\
\hline Column & S355 & 210 & 355 & 510 & 0.0031 & 0.30 & 0.215 \\
Beams & S275 & 210 & 275 & 430 & 0.0030 & 0.30 & 0.223 \\
WHP & SS-D 2205 & 200 & 591 & 722 & - & 0.30 & 0.091 \\
PT Bars & Class 10.9 & 200 & 900 & 1000 & 0.00855 & 0.30 & 0.063 \\
Rebars & B500A & 202 & 541 & 652 & 0.0022 & 0.30 & 0.25 \\
\hline
\end{tabular}

Table 2: Geometry of the composite beams' tests (According to [52] and [53])

\begin{tabular}{|c|c|c|c|c|c|c|c|c|}
\hline \multirow{2}{*}{$\begin{array}{l}\text { Composite } \\
\text { Beams }\end{array}$} & \multicolumn{3}{|c|}{ Concrete Section } & \multicolumn{4}{|c|}{ Steel Section } & \multirow{2}{*}{$\begin{array}{c}\text { Shear } \\
\text { Studs } \\
n_{\mathrm{c}}\end{array}$} \\
\hline & $L$ & $B$ & $t$ & $h$ & $b_{\mathrm{f}}$ & $t_{\mathrm{f}}$ & $t_{\mathrm{w}}$ & \\
\hline & & & & $\mathrm{nm}]$ & & & & [ ] \\
\hline $\begin{array}{l}\mathrm{CB} 1 \& \text { \&B2 } \\
{[52] \&[53]}\end{array}$ & 45000 & 600 & 120 & 206.8 & 133.9 & 9.6 & 6.4 & 12 \\
\hline
\end{tabular}

Table 3: Material properties of the composite beams' tests (According to [52] and [53]).

\begin{tabular}{|c|c|c|c|c|c|c|c|c|c|c|c|c|c|}
\hline \multirow{2}{*}{$\begin{array}{c}\text { Composite } \\
\text { Beams } \\
\end{array}$} & \multicolumn{2}{|c|}{ Concrete } & \multicolumn{3}{|c|}{ Steel beam flange } & \multicolumn{3}{|c|}{ Steel beam web } & \multicolumn{3}{|c|}{ Rebars } & \multicolumn{2}{|c|}{ Shear studs } \\
\hline & $f_{\mathrm{c}}$ & $f_{\mathrm{t}}$ & $f_{\mathrm{y}}$ & $f_{\mathrm{u}}$ & $E$ & $f_{\mathrm{y}}$ & $f_{\mathrm{u}}$ & $E$ & $f_{\mathrm{y}}$ & $f_{\mathrm{u}}$ & $E$ & $\mathrm{Q}_{\mathrm{u}}$ & $\Delta_{\mathrm{u}}$ \\
\hline & \multicolumn{11}{|c|}{ [ MPa ] } & {$[\mathrm{kN}]$} & {$[\mathrm{mm}]$} \\
\hline CB1 [52] & 29.5 & 3.6 & 352 & 529 & 200 & 387 & 537 & 227 & 547 & 641 & 199 & 110 & 12 \\
\hline CB2 [53] & 24.1 & 4.3 & 333 & 499 & $210^{*}$ & 359 & 510 & $210^{*}$ & 541 & 652 & $210^{*}$ & 100 & 10 \\
\hline
\end{tabular}

${ }^{*}$ No value is provided in [52]. Typical values are assumed.

Table 4: Yield and ultimate capacities of single-bolt rows in tension and compression.

\begin{tabular}{ccccc}
\hline & \multicolumn{2}{c}{ Tensile capacities } & \multicolumn{2}{c}{ Compressive capacities } \\
\cline { 2 - 5 } Failure mode & $t_{\mathrm{y}}$ (yield) & $t_{\mathrm{u}}$ (ultimate) & $c_{\mathrm{y}}$ (yield) & $c_{\mathrm{u}}$ (ultimate) \\
\hline Bearing at bolt hole & $1.5 L_{\mathrm{c}} t F_{\mathrm{y}} \leq 3.0 d t F_{\mathrm{y}}$ & $1.5 L_{\mathrm{c}} t F_{\mathrm{u}} \leq 3.0 \mathrm{dtF} F_{\mathrm{u}}$ & $3.0 d t F_{\mathrm{y}}$ & $3.0 d t F_{\mathrm{u}}$ \\
Bolt shear & $0.75 F_{\mathrm{v}} A_{\mathrm{b}}$ & $F_{\mathrm{v}} A_{\mathrm{b}}$ & $0.75 F_{\mathrm{v}} A_{\mathrm{b}}$ & $F_{\mathrm{v}} A_{\mathrm{b}}$ \\
\hline
\end{tabular}

$F_{\mathrm{v}}=517 \mathrm{MPa}(75 \mathrm{ksi})$ for ASTM A325 bolts (ASTM 2010a) and $F_{\mathrm{v}}=646 \mathrm{MPa}(94 \mathrm{ksi})$ for ASTM bolts both with threads excluded from the shear plane. 